\title{
INVESTIMENTO EM INTANGÍVEL E CRIAÇÃO DE VALOR: UMA ANÁLISE DAS COMPANHIAS ABERTAS BRASILEIRAS NO PERÍODO 2000-2014
}

\author{
Ronan Cunha * \\ Fernanda Finotti C. Perobelli ${ }^{\dagger}$ \\ EdUARdo GONÇALVES ‡
}

\begin{abstract}
Resumo
Este artigo analisa a relação entre investimentos em ativos intangíveis e criação de valor das empresas brasileiras de capital aberto no Brasil, medida pelo Q de Tobin. No artigo, aplica-se o system GMM em um painel de dados formado por 208 firmas com ações negociadas na Bolsa de Valores (B3) brasileira no período 2000-2014. Os dados são provenientes da Economática e Instituto Nacional de Propriedade Industrial (INPI). O principal resultado mostra impactos positivos do fluxo de investimento em ativos intangíveis (mas não seu acúmulo) sobre o valor das empresas.
\end{abstract}

Palavras-chave: Capital Intangível; Patentes; Valor de Mercado; Empresas Brasileiras.

\begin{abstract}
This article analyses the relationship between investment in intangible assets and value creation (measured by Tobin's Q) by the publicly traded Brazilian companies. The article uses the system GMM method for longitudinal data in 208 firms in the Brazilian stock exchange B3 during the period from 2000-2014. We use data from Economatica and Brazilian Patent Office (INPI). The main results indicate that investments' flow in intangible assets (but not its accumulation) positively affects the firm's market value.
\end{abstract}

Keywords: Intangible Capital; Patents; Market Value; Brazilian Firms. JEL classification: L10, O31, G32.

DOI: http ://dx.doi.org/10.11606/1980-5330/ea119149

\footnotetext{
* Doutorando em Economia na Escola de Economia de São Paulo - FGV. E-mail: cunha.ronan@gmail.com

${ }^{\dagger}$ Professora da Faculdade de Economia - Universidade Federal de Juiz de Fora. E-mail: fernandafinotti.perobelli@ufjf.edu.br

$\ddagger$ Professor da Faculdade de Economia - Universidade Federal de Juiz de Fora e Pesquisador do CNPq. E-mail: eduardo.goncalves@ufjf.edu.br
} 


\section{Introdução}

Inovação é uma das principais forças promotoras do crescimento econômico, principalmente por meio do seu impacto sobre a produtividade (Schumpeter 2013, Arrow 1971, Romer 1986, 1990). O aumento da produtividade permite tanto a redução dos custos de produção e, consequentemente, redução dos preços dos bens, quanto o desenvolvimento de novos e melhores produtos.

Não é surpresa que investimento em pesquisa e desenvolvimento (P\&D) e ativos intangíveis tenham ganhado mais importância na contabilidade das empresas nas últimas décadas. Lev \& Daum (2004) assinalam a existência de um aumento nos investimentos em ativos intangíveis das firmas após 1980 . Segundo Ocean (2015), o capital intangível representa atualmente cerca de $84 \%$ do valor das empresas que compõem o indicador S\&P500, principalmente índice da bolsa americana NYSE, contrastando com o valor de 17\% de 1975.

Investimento em intangíveis é uma forma de diferenciar as empresas frente aos concorrentes (Lev 2000). Penrose (2009), Nonaka \& Takeuchi (2004) e Teece (2010) defendem que capital intangível é composto por ativos específicos das firmas, difíceis de serem copiados, que aumentam sua competitividade frente às concorrentes. Investimentos bem-sucedidos em capital intangível têm o potencial de alterar o fluxo de caixa futuro das empresas e, consequentemente, aumentar o seu valor de mercado (Griliches 1981).

Entretanto, ainda existe dificuldade em mensurar o capital intangível de uma empresa. Na literatura, esse conceito é muito amplo e sua origem ainda não é um consenso ${ }^{1}$. Define-se ativo intangível como fontes não monetárias e não físicas de recursos com probabilidade positiva de futuro retorno econômico (Cañibano et al. 2000). Já Lev (2000) define ativos intangíveis de forma mais objetiva, como fontes não físicas de valor, com promessas de benefícios futuros, gerados por inovação, desenho organizacional ou práticas de recursos humanos únicos. Nos trabalhos empíricos, observa-se que capital intangível é definido como marcas, patentes, $\mathrm{P} \& \mathrm{D}$, gastos com publicidade e propaganda, capital social, etc. Essas variáveis não são substitutas, mas complementares. Acredita-se que cada uma delas componha parte do capital intangível das empresas e sua soma deveria representar todo o seu ativo intangível.

Baseados nos modelos de precificação hedônicos, alguns trabalhos na literatura internacional mostram os impactos dos ativos intangíveis sobre o valor de mercado das empresas. Aboody \& Lev (1998), Nagaoka (2006) e Sandner \& Block (2011) mostram o efeito positivo de investimentos em P\&D no valor das empresas americanas, japonesas e europeias, respectivamente; Belenzon \& Patacconi (2013) encontram que o estoque de patentes de empresas europeias adquiridas no ano anterior à aquisição tem um efeito positivo sobre o valor das empresas adquirentes após a aquisição; Nagaoka (2006), Oliveira et al. (2010) e Sandner \& Block (2011) afirmam que investimentos em marcas também aumentam o valor das empresas.

No Brasil, a importância dos ativos intangíveis na criação de valor das empresas é verificada por meio de ativos diferidos ou patrimônio da marca (Alencar \& Dalmacio 2006, Magro et al. 2015, da Silva et al. 2017), quantidade de marcas, tempo médio de validade de patentes (Teh et al. 2008) e conta de ativos intangíveis (Magro et al. 2015, da Silva et al. 2017). Entretanto, o estoque

\footnotetext{
${ }^{1}$ Cañibano et al. (2000) fazem uma extensa revisão sobre a definição e origem dos ativos intangíveis.
} 
de patentes continua sem evidências de efeito significativo, dentre outros, Teh et al. (2008). Outra maneira utilizada para investigar o efeito do capital intangível no valor das firmas, avaliando um conceito mais amplo, é mensurando o nível de intangibilidade das firmas (Kayo 2002, Kayo et al. 2006, Belém \& Marques 2012).

Com base no modelo de Griliches (1981), este artigo considera que a criação de valor nas firmas brasileiras, representada pelo $Q$ de Tobin, é uma função do conjunto de seus ativos tangíveis e intangíveis. O principal objetivo é analisar o efeito do capital intangível, contemplando diferentes definições de intangível encontradas na literatura, sobre o valor de mercado das firmas. Para tal, mede-se capital intangível de quatro formas distintas e complementares neste trabalho: 1) estoque de patentes, representando a qualidade do investimento ou o sucesso da atividade de pesquisa, seguindo Hall et al. (2007); 2) estoque de marcas, representando o capital consumidor; 3 ) fluxo de ativos intangíveis, medindo o investimento realizado em capital intangível em um certo período, exceto gastos com patentes e marcas; e 4) grau de intangibilidade total da firma, representando o estoque de investimentos já realizados em intangíveis pela empresa ao longo de um período, um conceito mais amplo (Kayo 2002, Kayo et al. 2009, Belém \& Marques 2012, Mendes Nascimento et al. 2012, Decker et al. 2013). Acredita-se que, por meio dessas quatro variáveis, a maior parte, se não todo o capital intangível da firma, esteja sendo incorporada na análise, permitindo que o efeito de cada parte do capital intangível no valor das empresas da amostra seja analisado.

Esse trabalho utiliza uma abrangente base de dados que contempla o período de 2000 a 2014 e é composta de informações trimestrais de 208 empresas listadas na Bolsa de Valores, Mercadorias e Futuros (B3), cobrindo 46 setores da economia brasileira entre os anos 2000 e 2014. As informações sobre a quantidade de marcas e patentes são provenientes do Instituto Nacional de Propriedade Industrial (INPI). As informações financeiras das empresas foram coletadas no sistema Economática.

Busca-se corrigir os vieses causados tanto pela endogeneidade gerada pelos efeitos fixos não observados das firmas quanto pela causalidade reversa do valor da empresa nos investimentos em ativos intangíveis (empresas com Q de Tobin maiores dispõem de mais recursos no mercado financeiro e podem utilizá-los para investir em capital intangível) por meio de técnicas estatísticas diferentes. Para o primeiro tipo de endogeneidade, aplica-se o método de efeitos fixos. Para o segundo, utilizam-se duas estratégias. A primeira é defasar as variáveis explicativas, como em Griliches (1981), Aboody \& Lev (1998), Alencar \& Dalmacio (2006) e Belenzon \& Patacconi (2013), tomando-se como premissa que o valor atual da empresa somente influencia a capacidade de investimentos presentes e futuros, não os passados. Essa estratégia tem a vantagem de ser de fácil implementação e operacionalizada utilizando o estimador de efeitos fixos. Entretanto, ela impõe restrições: perde-se o efeito contemporâneo entre as variáveis, assume-se um modelo estático, o que pode induzir autocorrelação nos resíduos, e impõe uma estrutura específica para as covariadas defasadas. Para essa última, devido às incertezas inerentes aos investimentos em intangíveis, é possível que seus efeitos ocorram em períodos diferentes.

A fim de superar essas restrições, aplica-se uma segunda estratégia metodológica, o system GMM (Arellano \& Bover 1995, Blundell \& Bond 1998). Essa estratégia consiste em estimar um modelo dinâmico com efeitos fixos 
não observáveis que permite avaliar o impacto contemporâneo entre as variáveis. A possibilidade de incluir o valor da empresa defasado como variável explicativa permite controlar por estruturas mais complexas de defasagens das covariadas.

Além da estratégia econométrica, utiliza-se uma longa série histórica de marcas e patentes, a fim de tornar a causalidade reversa menos provável. Para reduzir o viés de variáveis omitidas, visto que existem outras dimensões que afetam o valor da empresa, adota-se a estratégia de considerar quatorze variáveis de finanças corporativas e aplica-se a análise fatorial, reduzindo-as a cinco fatores $^{2}$ : tamanho da firma, liquidez contábil, retorno do acionista, risco e retorno da firma e singularidade.

Os resultados mostram efeitos positivos, mas defasados, ou seja, sem nenhum efeito contemporâneo, do estoque de marcas sobre o valor das empresas. Por outro lado, o fluxo de intangíveis apresentou forte efeito positivo contemporâneo sobre o valor, enquanto que o seu efeito passado não foi robusto. Esses resultados, juntamente com o efeito ambíguo do estoque de patentes e do grau de intangibilidade sobre o valor das empresas brasileiras, sugerem que o mercado ainda pauta o desenvolvimento tecnológico das empresas brasileiras na imitação e difusão (Kanwar \& Hall 2015), valorizando o investimento em ativos intangíveis principalmente para a manutenção do capital e da competitividade. O acúmulo de investimentos em intangíveis ainda é visto de forma ambígua pelos investidores, devido à opacidade desse tipo de ativo, que o torna de difícil avaliação ao longo do tempo, quando comparado aos ativos tangíveis.

Esse trabalho se divide em mais 4 seções, além dessa introdução. Na Seção 2 é feita uma revisão teórica e empírica dos modelos que relacionam o valor das firmas com ativos intangíveis nas suas variadas definições. A Seção 3 descreve o modelo econométrico, a estratégia de estimação, o banco de dados e a construção das variáveis. Na Seção 4, são apresentados os resultados e as análises econométricas. A última seção conclui o estudo.

\section{Revisão da Literatura}

De acordo com a teoria de precificação de ativos, o valor da empresa observado no mercado financeiro (preço) representa o seu fluxo de caixa futuro esperado descontado ao valor presente. Os investidores observam tanto dados contábeis das empresas quanto o mercado no qual ela está inserida para realizarem tais projeções. Nessa abordagem, as empresas são consideradas um conjunto de ativos, cada um deles valorizado pelo investidor de acordo com sua contribuição para o fluxo de caixa (Hall et al. 2007). Assim, se investidores acreditam que ativos intangíveis trazem valor para empresa, eles estariam sendo contabilizados no seu preço de mercado. Uma das hipóteses subjacentes a essa abordagem é a de que os mercados são eficientes e os investidores se comportam racionalmente (Fama 1970). Um modelo seminal de avaliação de intangíveis baseado nessa abordagem é Griliches (1981), que define o valor da empresa pela Equação (1):

$$
V=\theta(T+\lambda I)^{\sigma}
$$

\footnotetext{
${ }^{2}$ Para testes de robustez, também foram gerados conjuntos de três a seis fatores.
} 
em que $T$ é o valor do estoque de capital tangível e $I$ é o valor de estoque do ativo intangível. Ambas as categorias de ativos são somadas para gerar o valor de uma empresa $(V)$. O parâmetro $\sigma$ mede os retornos de escala e é igual a um se a função valor é homogênea de grau um, indicando retornos constantes à escala de cada componente (Pemberton \& Rau 2015). $\theta$ é o inverso da taxa de desconto (retorno do capital) e reflete o risco da firma e do mercado em que está inserida. Griliches (1981) assume que essa taxa é função exponencial dos efeito fixos das firmas $(\alpha)$, efeitos fixos do tempo $(\delta)$ e um termo idiossincrático $(\epsilon), \theta=e^{\alpha+\delta+\epsilon}$. O valor marginal $\lambda$ reflete a contribuição para o valor da empresa quando uma unidade adicional é gasta com ativos intangíveis. Quando $\sigma=1, \lambda$ é o preço sombra relativo aos ativos intangíveis (Hall \& Oriani 2006). Colocando a Equação (1) em termos relativos ao ativo total da firma $(T)$, define-se $q=V / T$, que pode ser interpretado como seu Q de Tobin:

$$
\frac{V}{T}=q=e^{\alpha+\delta+\epsilon} T^{\sigma-1}\left(1+\lambda \frac{I}{T}\right)^{\sigma}
$$

Tomando o logaritmo de ambos os lados, tem-se a equação para o Q de Tobin da empresa $i$ no tempo $t$ :

$$
\ln \left(q_{i t}\right)=\ln \left(\frac{V_{i t}}{T_{i t}}\right)+\alpha_{i t}+\delta_{t}+(\sigma-1) \ln \left(T_{i t}\right)+\sigma \ln \left(1+\lambda \frac{I_{i t}}{T_{i t}}\right)+\epsilon_{i t}
$$

Apesar de simples, a análise empírica desse modelo enfrenta vários desafios. A começar pela própria definição de ativo intangível (I). Das definições mais abrangentes, Cañibano et al. (2000) resumem ativo intangível como fontes não monetárias e não físicas, com probabilidade positiva de futuro retorno econômico, que foi adquirido ou gerado internamente pela firma por meio de custos identificados, com tempo de duração limitada e com valoração de mercado à parte da entidade. Já Lev (2000) define ativos intangíveis de forma mais objetiva, como fontes não físicas de valor (com promessas de benefícios futuros) gerados por inovação, desenho organizacional ou práticas de recursos humanos únicos. De forma semelhante, Lönnqvist \& Mettänen (2002) definem ativos intangíveis como fonte não material de criação de valor baseado na capacidade de empregados, recursos organizacionais e na forma como a firma operacionaliza e se relaciona com os contribuintes. A definição contábil brasileira está na Lei $N^{\circ} 11.638$ de $28.12 .2007^{3}$, "os direitos que tenham por objeto bens incorpóreos destinados à manutenção da companhia ou exercidos com essa finalidade, inclusive o fundo de comércio adquirido". Desde a promulgação dessa lei, os ativos passíveis de serem classificados como intangíveis pela legislação mereceram condição de destaque entre os ativos das firmas.

Empiricamente, o cálculo do montante que pode ser considerado intangível é feito de diferentes maneiras (Tabela 1). Os conceitos mais comuns são gastos com P\&D, quantidade de patentes e marcas (Griliches 1981, Aboody \& Lev 1998, Nagaoka 2006, Teh et al. 2008, Oliveira et al. 2010, Sandner \& Block 2011, Belenzon \& Patacconi 2013). Trabalhos como Chen \& Chang (2010) também medem ativos intangíveis ponderando-os pela sua qualidade ou abrangência, por meio de indicadores como a quantidade de citações das

\footnotetext{
${ }^{3}$ da Silva Junior \& Pereira (2015) fazem uma descrição detalhada e analítica sobre as mudanças contábeis após a Lei 11.638/07.
} 
patentes e concentração em áreas de conhecimento. Outros autores utilizam a definição contábil aceita em alguns países, como o Brasil (Kayo et al. 2009) e os Estados Unidos (Magro et al. 2015).

Dos diferentes tipos de ativos intangíveis testados na literatura, é interessante verificar que a quantidade de marcas utilizada (Teh et al. 2008, Oliveira et al. 2010, Sandner \& Block 2011) e os gastos com P\&D (Griliches 1981, Aboody \& Lev 1998, Nagaoka 2006, Sandner \& Block 2011) possuem efeitos positivos e significativos sobre valor das firmas, enquanto que a quantidade de patentes não é significativa na maioria desses trabalhos (Tabela 1). As únicas exceções são os trabalhos de Griliches (1981) e Belenzon \& Patacconi (2013).

A utilização de variáveis defasadas (Griliches 1981, Aboody \& Lev 1998, Alencar \& Dalmacio 2006, Belenzon \& Patacconi 2013) pode ser uma estratégia para lidar com a endogeneidade no modelo causada pelo efeito reverso (feedback) entre o valor da empresa e os investimentos em $\mathrm{P} \& \mathrm{D}$, estoques de patentes, marcas e ativos intangíveis totais. Empresas com maiores Q de Tobin têm mais facilidade de adquirir recursos no mercado financeiro e podem utilizá-los para financiar seus investimentos em capital intangível.

Dois trabalhos utilizaram o investimento em P\&D e estoque de patentes defasadas, Griliches (1981) e Aboody \& Lev (1998). O primeiro autor utiliza as variáveis de gastos com $\mathrm{P} \& \mathrm{D}$ defasados e inclui seis defasagens, enquanto que o estoque de patentes é uma variável contemporânea em seu modelo. Ele encontra que duas das defasagens de $\mathrm{P} \& \mathrm{D}$ são positivas e significativas (a primeira e a sexta) e a quinta é negativa e significativa. O estoque de patentes contemporâneo também é positivo e significativo. Esse autor também analisa o efeito de gasto com $\mathrm{P} \& \mathrm{D}$ e estoque de patentes previstos e não previstos. Seus resultados mostram que ambos gastos com $P \& D$ e ambas quantidades de patentes têm um efeito positivo e significativo.

Aboody \& Lev (1998) analisam as empresas de software e o estoque de patentes em seu modelo é o valor patrimonial dos ativos de software, argumentando que essa é uma medida muito melhor para o estoque de patentes do que a simples quantidade. Os autores utilizaram duas especificações, uma contemporânea, em que regrediram o preço das ações contra o valor patrimonial dos softwares, e outra em que regrediram o retorno das ações contra os gastos com desenvolvimento de softwares defasados em até três períodos, utilizando dados anuais de 1987 a 1995 para empresas americanas. Os resultados mostram que tanto o valor patrimonial dos softwares quanto os gastos com desenvolvimento de softwares do ano anterior são positivamente relacionados com o preço e retorno, respectivamente, das empresas.

Tem-se conhecimento somente do trabalho de Kanwar \& Hall (2015) que aplica o system GMM para empresas indianas de 2000 a 2010. Entretanto, esse autor não consegue validar suas estimações ao utilizar tal método. Suas estimações não passaram nos testes de sobreidentificação de Hansen (1982). Ele também utiliza o estimador de variáveis instrumentais, no qual os instrumentos eram as variáveis defasadas, mas o próprio autor argumenta que o passado das variáveis das firmas não são bons instrumentos e baseia suas análises nas estimativas com mínimos quadrados ordinários defasados.

No Brasil, alguns trabalhos encontram uma relação positiva entre ativos intangíveis e o valor de mercado das empresas. Pode-se dividir os trabalhos analisados entre aqueles que utilizam análises comparativas de grupos e aqueles que adotam métodos de regressão linear. 
Tabela 1: Trabalhos empíricos sobre o valor da firma e ativos intangíveis

\begin{tabular}{|c|c|c|c|c|c|c|c|}
\hline Autor & Período & Observações & Geografi & Método & Medida de Valor & Variáveis de interesse & Resultados \\
\hline Griliches (1981) & $\begin{array}{l}1968- \\
1974\end{array}$ & 157 firmas & USA & $\mathrm{EF}$ & Q de Tobin & $\begin{array}{l}\text { P\&D defasado até } 6 \text { períodos } \\
\text { Surpresa em P\&D } \\
\text { P\&D previsto } \\
\text { Quantidade de patentes } \\
\text { Patentes previstas } \\
\text { Surpresa em patentes }\end{array}$ & $\begin{array}{l}+ \\
+ \\
+ \\
+ \\
+ \\
+\end{array}$ \\
\hline $\begin{array}{l}\text { Aboody \& Lev } \\
(1998)\end{array}$ & $\begin{array}{l}1987- \\
1995\end{array}$ & 186 firmas & USA & MQO & $\begin{array}{l}\text { Variação no } \\
\text { preço } \\
\text { Preço da ação }\end{array}$ & $\begin{array}{l}\text { Valor capitalizado para software } \\
\text { Gastos com software } \\
\text { Gastos com software de investidores } \\
\text { Variação investimento + gastos em software } \\
\text { Variação de gastos com software } \\
\text { Variação investimento em software } \\
\text { Valor acumulado líquido dos softwares }\end{array}$ & $\begin{array}{l}\text { NS } \\
+ \\
+ \\
+ \\
N S \\
N S \\
+\end{array}$ \\
\hline Nagaoka (2006) & $\begin{array}{l}1991- \\
2000\end{array}$ & 726 firmas & Japão & $\mathrm{EF}$ & Q de Tobin & $\begin{array}{l}\text { Gasto com } \mathrm{P} \& \mathrm{D} \\
\text { Gasto com propaganda } \\
\text { Estoque de patentes }\end{array}$ & $\begin{array}{c}+ \\
+ \\
+ \\
N S\end{array}$ \\
\hline Teh et al. (2008) & 2003 & 216 firmas & Brasil & MQO & $\begin{array}{l}\text { Valor de mer- } \\
\text { cado/valor } \\
\text { contábil }\end{array}$ & $\begin{array}{c}\text { Quantidade de patentes } \\
\text { Quantidade de marcas } \\
\text { Tempo médio de validade das patentes } \\
\text { Quantidade de patentes } \\
\text { Quantidade de marcas } \\
\text { Tempo médio de validade das patentes }\end{array}$ & $\begin{array}{l}N S \\
+ \\
N S \\
N S \\
+ \\
-\end{array}$ \\
\hline $\begin{array}{l}\text { Kayo et al. } \\
(2006)\end{array}$ & $\begin{array}{l}1996- \\
2007\end{array}$ & $\begin{array}{l}164 \text { anúncios } \\
\text { de aquisição }\end{array}$ & Brasil & MQO & $\begin{array}{l}\text { Retorno anor- } \\
\text { mal }\end{array}$ & $\begin{array}{c}\text { Nível de intangibilidade } \\
\text { Nível de intangibilidade } \times \text { endividamento }\end{array}$ & $\begin{array}{c}N S \\
-\end{array}$ \\
\hline
\end{tabular}

Nota: MQO significa mínimos quadrados ordinários, EF significa efeito fixo, PD significa primeira diferença e MQNL significa

mínimos quadrados não lineares.

* Contratos de fusão e aquisição.

Fonte: Os autores. 
Tabela 1: Trabalhos empíricos sobre o valor da firma e ativos intangíveis (continuação)

\begin{tabular}{|c|c|c|c|c|c|c|c|}
\hline Autor & Período & Observações & Geografia & Método & Medida de Valor & Variáveis de interesse & Resultados \\
\hline $\begin{array}{l}\text { Oliveira et al. } \\
(2010)\end{array}$ & $\begin{array}{l}1998- \\
2008\end{array}$ & 354 firmas & Portugal & $\mathrm{EF}$ & Preço da ação & $\begin{array}{l}\text { Ativos intangíveis no BP } \\
\text { Outros ativos intangíveis } \\
\text { Patrimônio da marca } \\
\text { Estoque de patentes }\end{array}$ & $\begin{array}{l}+ \\
+ \\
+ \\
N S\end{array}$ \\
\hline $\begin{array}{l}\text { Chen \& Chang } \\
(2010)\end{array}$ & $\begin{array}{l}1997- \\
2006\end{array}$ & $\begin{array}{l}37 \text { firmas far- } \\
\text { macêuticas }\end{array}$ & USA & $\mathrm{EF}$ & $\begin{array}{l}\text { Valor de mer- } \\
\text { cado }\end{array}$ & $\begin{array}{c}\text { Posição relativa de patente } \\
\text { Vantagem tecnológica revelada } \\
\text { Índice Herfindahl de patentes } \\
\text { Citações de patentes }\end{array}$ & $\begin{array}{l}+ \\
\text { NS } \\
- \\
+\end{array}$ \\
\hline $\begin{array}{l}\text { Sandner } \\
\text { Block }(2011)\end{array}$ & $\begin{array}{l}1996- \\
2002\end{array}$ & 1216 firmas & Europa & MQNL & Q de Tobin & $\begin{array}{l}\text { Estoque de P\&D } \\
\text { Estoque de patentes } \\
\text { Estoque de citações } \\
\text { Estoque de marcas }\end{array}$ & $\begin{array}{l}+ \\
N S \\
+ \\
+\end{array}$ \\
\hline $\begin{array}{l}\text { Belenzon \& Pata } \\
\text { coni }(2013)\end{array}$ & $\begin{array}{l}-1985- \\
2007\end{array}$ & $33.000 \mathrm{~F} \& \mathrm{~A}^{*}$ & $\begin{array}{l}\text { USA e } \\
\text { Europa }\end{array}$ & MQO & $\begin{array}{l}\text { Valor da firma } \\
\text { após aquisição }\end{array}$ & $\begin{array}{l}\text { Patentes das firmas americanas antes da } \\
\text { aquisição } \\
\text { Patentes das firmas europeias antes da } \\
\text { aquisição }\end{array}$ & $\begin{array}{l}\text { NS } \\
+\end{array}$ \\
\hline $\begin{array}{l}\text { Bontempi \& } \\
\text { Mairesse (2015) }\end{array}$ & $\begin{array}{l}1982- \\
1999\end{array}$ & 14.254 firmas & Itália & $\mathrm{PD}$ & $\begin{array}{l}\text { Valor agregado } \\
\text { / trabalhador }\end{array}$ & $\begin{array}{l}\text { Capital intengível } \\
\text { Capital intelectual } \\
\text { Capital consumidor }\end{array}$ & $\begin{array}{l}+ \\
+ \\
+\end{array}$ \\
\hline $\begin{array}{l}\text { Kanwar \& Hall } \\
\text { (2015) }\end{array}$ & $\begin{array}{l}2001- \\
2010\end{array}$ & 380 firmas & Índia & $\begin{array}{l}\text { EF e } \\
\text { MQNL }\end{array}$ & Q de Tobin & $\begin{array}{c}\text { Fluxo de P\&D } \\
\text { Ativo intangível } \\
\text { Qualidade do capital intangível }\end{array}$ & $\begin{array}{l}+ \\
+ \\
+\end{array}$ \\
\hline
\end{tabular}

Nota: MQO significa mínimos quadrados ordinários, EF significa efeito fixo, PD significa primeira diferença e MQNL significa mínimos quadrados não lineares.

* Contratos de fusão e aquisição.

Fonte: Os autores. 
Entre os estudos do primeiro grupo, apesar da semelhança em termos de metodologia e medida de intangibilidade, a saber, valor de mercado das empresas dividido pelo patrimônio líquido contábil, Kayo (2002) e Belém \& Marques (2012) encontram resultados diferentes de Mendes Nascimento et al. (2012) e Decker et al. (2013). Utilizando uma amostra de 366 empresas de 1998 a 2001, Kayo (2002) afirma que empresas intensivas em intangíveis têm menores níveis de endividamento e que essas empresas, quando maduras, apresentam maiores níveis de rentabilidade, fluxos de caixa e, como esperado, maiores riscos. Perez \& Famá (2006), utilizando 699 empresas americanas de 1997 e 2002, e Belém \& Marques (2012), analisando 180 empresas brasileiras de 2000 a 2010, também concluem que a rentabilidade, medida pelo retorno sobre o patrimônio líquido e o retorno sobre o ativo, é maior para empresas intensivas em capital intangível. Por outro lado, Mendes Nascimento et al. (2012) utilizam uma base menor, com 28 empresas dos setores de Telecomunicações e Tecnologia da Informação para o ano de 2008, afirmando que o grau de intangibilidade não está correlacionado com a rentabilidade (ROA e ROE) dessas empresas.

Os estudos que aplicam métodos de regressão linear são metodologicamente mais abrangentes. Alencar \& Dalmacio (2006) mostram que existe uma relação positiva e significativa entre o ativo diferido das empresas e os preços das ações no próximo período. Os autores aplicam o método de MQO, controlando apenas pelo patrimônio líquido e lucro líquido, em uma amostra que cobre os anos de 2000 a 2004 de 324 empresas brasileiras listadas na B3.

Teh et al. (2008), também aplicando o método de MQO em 216 empresas para o ano de 2003, estabelecem que maiores quantidades de marcas aumentam o valor da empresa. Os autores utilizam duas medidas de valor: a primeira é o valor de mercado das ações dividido pelo seu valor patrimonial; a segunda é o Q de Tobin, que os autores calculam como a soma do valor de mercado da empresa, das debentures, financiamentos, disponibilidades e investimentos de curto e longo prazo e adiantamentos de contratos de câmbio dividido pelo valor do ativo total. O tempo médio de validade de patentes é positivo e significativo apenas para a razão valor de mercado-valor contábil. Assim como na literatura internacional, a quantidade de patentes também não mostrou efeito significativo e a quantidade de marcas apresentou impacto positivo e significativo sobre o valor da empresa para ambas as variáveis dependentes.

Utilizando Q de Tobin para medir o nível de intangibilidade, em vez do valor da empresa, Kayo et al. (2009) não encontram um efeito significativo sobre o retorno acumulado de 164 empresas adquiridas no período de 1996-2007. Já a interação do Q de Tobin com o endividamento é negativa e significativa, isto é, financiar investimentos em intangível via endividamento é visto como uma decisão ruim pelo mercado. Por outro lado, Belém \& Marques (2012), ao aplicarem o método de efeitos fixos, descobrem que o nível de intangibilidade, medido pelo valor de mercado das empresas dividido pelo patrimônio líquido contábil, tem um efeito significativo e positivo sobre a rentabilidade do capital e do ativo das empresas. Os autores controlam pelo tamanho do ativo da empresa e endividamento.

Magro et al. (2015) e da Silva et al. (2017) testam o efeito da conta ativos intangíveis e ativos diferidos (patrimônio da marca), após a Lei 11.638/07. Para tal, também utilizam os mesmos controles, como patrimônio e lucro líquido ajustados pelos ativos intangíveis, e o método de efeitos fixos. A diferença 
recai nas empresas analisadas. Magro et al. (2015) selecionam 114 empresas de baixa e cinco de alta tecnologia e encontram que ambas as variáveis de interesse têm um efeito positivo e significativo no preço futuro das ações das empresas. Já da Silva et al. (2017) não fazem essa distinção entre o nível tecnológico das empresas. Eles coletam dados para 164 empresas listadas na B3 e chegam às mesmas conclusões que Magro et al. (2015).

Concluída a revisão, argumenta-se que este trabalho contribua para a literatura brasileira ao analisar o impacto de ativos intangíveis sobre o valor da empresa, sendo esses ativos medidos de acordo com quatro diferentes conceitos encontrados na literatura e tendo por base o modelo de Griliches (1981). Esses quatro conceitos são: estoque de marcas e de patentes, fluxo de investimento em ativos intangíveis e grau de intangibilidade das firmas. Dessa maneira, acredita-se que grande parte, se não todo o capital intangível das empresas, esteja sendo incorporado ao modelo. A base de dados foi cuidadosamente preparada para que, juntamente com a estratégia econométrica, houvesse redução do viés causado por variáveis omitidas ou endogeneidade.

\section{Metodologia}

\subsection{Modelo econométrico}

Seguindo o modelo de Griliches (1981), o modelo a ser estimado (Equação (5)) é baseado na Equação (3). A fim de ser abrangente na definição de ativo intangível, foram utilizadas quatro variáveis com base nos diferentes conceitos de capital intangível e que, juntas, substituirão o termo $I / T$ da Equação (3). O capital intangível das firmas é formado pelo conjunto de variáveis na Equação (4), aplicando a aproximação $\ln (1+x) \approx x$ :

$$
\ln \left(1+\lambda \frac{I_{i t}}{T_{i t}}\right)=\theta_{1} \text { Qmarcas }_{i t}+\theta_{2} \text { Qpat }_{i t}+\theta_{3} \text { Fint }_{i t}+\theta_{4} G_{i t}
$$

na qual Fintg $g_{i t}$ representa o fluxo de investimento em ativos intangíveis, exceto patentes e marcas, entre o período $t$ e $t-1$; Qmarcas $_{i t}$ são, respectivamente, o estoque de patentes e marcas da firma $i$ no período $t$. $G I_{i t}$ é a definição contábil brasileira para o estoque de ativos intangíveis divulgado nos balanços das empresas, sendo medido pelo logaritmo do estoque de ativos intangíveis dividido pelo ativo total da empresa. Essa última variável é interpretada como o grau de intangibilidade da empresa. Acredita-se que a Equação (4) inclua grande parte de todo o capital intangível das empresas. Algumas medidas estão mais desagregadas, como estoque de patentes e estoque de marcas, enquanto outras estariam mais agregadas, como fluxos de intangíveis e grau de intangibilidade. A omissão de parte desse capital poderia enviesar os resultados. A construção detalhada dessas variáveis está na Subseção 3.1.

Enquanto os termos de Equação (4) darão conta de sensibilizar o valor da firma pelo componente intangível, há diversas outras variáveis que geram valor pela utilização do componente tangível. A literatura empírica e teórica na área de finanças sugere um grande conjunto dessas variáveis. Para evitar o viés de variáveis omitidas e, ao mesmo tempo, não incluir muitas variáveis de controle, que poderiam estar muito correlacionadas entre si, optou-se por fazer como Lima \& Carmona (2011), que incluem fatores calculados pelo método de Análise Fatorial. Esse método, além de sintetizar as variáveis de controle, 
ainda garante a ortogonalidade entre as variáveis. Nesse trabalho, utilizaramse 14 variáveis que foram sintetizadas em cinco fatores ${ }^{4}$ : tamanho da firma, liquidez contábil, rentabilidade dos sócios, risco e retorno da firma e singularidade. Esses fatores são descritos com mais detalhes no Apêndice.

Um problema presente em estimações econométricas com variáveis contábeis é a causalidade reversa. Nesse caso, ele ocorre entre o valor da empresa e investimento em ativos intangíveis. Empresas mais valiosas têm acesso a mais recursos nos mercados e podem utilizá-los para financiar outros ativos intangíveis e tangíveis. Aplicam-se duas estratégias nesse trabalho para lidar com a endogeneidade. A primeira é defasar as variáveis explicativas, seguindo os trabalhos de Griliches (1981), Aboody \& Lev (1998), Alencar \& Dalmacio (2006), Kanwar \& Hall (2015), Magro et al. (2015) e da Silva et al. (2017). Assim, a especificação a ser estimada é:

$$
\begin{array}{r}
\ln \left(q_{i t}\right)=\beta_{0}+\beta_{1} \text { Q }_{\text {marcas }_{i t-1}}+\beta_{2} \text { Qpat }_{i t-1}+\beta_{3} \text { Fintg }_{i t-1}+\beta_{4} \text { GI It }-1_{i}+ \\
+\sum_{k=1}^{K} \gamma_{k} f_{i t-1 k}+\gamma T_{i t-1}+\sum_{k=1}^{J} \pi_{k} m_{i t-1 k}+\alpha_{i}+\delta_{t}+\epsilon_{i t}
\end{array}
$$

na qual $f_{i t-1 k}$ são os $\mathrm{K}$ fatores que controlam as características observadas das firmas e, $T_{i t-1}$ é o grau de tangibilidade das firmas, medido como o valor do ativo tangível dividido pelo ativo total das firmas, $m_{i t-1 k}$ são $J$ as variáveis macroeconômicas, $\alpha_{i}$ é o efeito fixo da empresa $i$ invariante no tempo, $\delta_{t}$ é o efeito do tempo $t$ comum a todas as firmas e que não foi capturada pelas variáveis macroeconômicas, como por exemplo, ambiente institucional, e $\epsilon_{i t}$ é o termo de erro assumido ser independente e identicamente distribuído como uma normal com média zero e variância constante. A estimação dessa equação é feita pelo método de efeitos fixos.

As consequências dessa estratégia são a perda da relação contemporânea entre o valor de mercado, suposição de um modelo estático e a imposição de uma estrutura para as variáveis defasadas. A segunda pode induzir a autocorrelação nos resíduos, que enviesa o erro-padrão. A fim de corrigir a correlação serial e, ao mesmo tempo, permitir estruturas mais complexas de defasagens das covariadas, deve-se incluir o Q de Tobin defasado. Griliches (1981) também inclui esse parâmetro autorregressivo em sua análise empírica. Entretanto, o estimador de efeitos fixos é enviesado em modelos dinâmicos (Arellano \& Bond 1991).

Esses problemas nos direcionam à segunda estratégia utilizada nesse estudo, que é aplicar o método dos momentos generalizados em painel dinâmico (Arellano \& Bover 1995, Blundell \& Bond 1998), conhecido como system GMM e também utilizado por Kanwar \& Hall (2015). Esse método permite a estimação de relações contemporâneas entre as variáveis, incluir o Q de Tobin defasado, controlar pelos efeitos fixos não observados e também comportar mais de uma variável endógena (Roodman 2006). Esse método é um sistema de duas equações, a Equação (6), em nível e a Equação (7), em primeira diferença.

\footnotetext{
${ }^{4}$ Para testes de robustez, também foram gerados conjuntos com três a seis fatores.
} 


$$
\begin{array}{r}
\ln \left(q_{i t}\right)=\theta_{0}+\theta_{1} \text { Qmarcas }_{i t}+\theta_{2} \text { Qpat }_{i t}+\theta_{3} \text { Fint }_{i t}+\theta_{4} G I_{i t}+ \\
+\sum_{k=1}^{K} \delta_{k} f_{i t k}+\delta T_{i t}+\sum_{k=1}^{J} \phi_{k} m_{i t k}+\alpha_{i}+\delta_{t}+\epsilon_{i t} \\
\Delta \ln \left(q_{i t}\right)=\Delta \theta_{1} \text { Qmarcas }_{i t}+\Delta \theta_{2} \text { Qpat }_{i t}+\Delta \theta_{3} \text { Fintg }_{i t}+\Delta \theta_{4} G I_{i t}+ \\
+\sum_{k=1}^{K} \delta_{k} \Delta f_{i t k}+\delta \Delta T_{i t}+\sum_{k=1}^{J} \phi_{k} \Delta m_{i t k}+\Delta \delta_{t}+\Delta \epsilon_{i t}
\end{array}
$$

O system GMM é baseado em dois conjuntos de momentos $E\left(X_{i t-j} \Delta \epsilon_{i t}\right)=0$ e $E\left(\Delta X_{i t-j} \epsilon_{i t}\right)=0$, em que $j \geq 2$. O primeiro momento implica que é possível utilizar as variáveis em nível como instrumentos para as variáveis endógenas na Equação (7). O segundo conjunto de momentos permite que o passado das variáveis diferenciadas seja utilizado como instrumentos para as variáveis endógenas da Equação (6). Os fatores macroeconômicos e as variáveis dummies são variáveis exógenas nesse modelo. A consistência do estimador se dá sob a hipótese de instrumentos válidos e ausência de autocorrelação nos resíduos da equação em nível. Essas hipóteses podem ser testadas utilizando o teste de sobreidentificação de Hansen (1982) e o teste de autocorrelação de Arellano \& Bond (1991), respectivamente.

\subsection{Base de dados}

Para a formação da amostra, foram consideradas 208 empresas registradas como sociedades por ações de capital aberto, com ações negociadas na B3 entre o primeiro trimestre de 2000 e o quarto trimestre de 2014, pertencentes a 46 setores $^{5}$ da economia brasileira.

As informações sobre quantidade de patentes e marcas foram obtidas na página eletrônica institucional do Instituto Nacional e Propriedade Industrial (INPI) e foram coletadas no site dessa instituição desde 1900, com base no nome e/ou no Cadastro Nacional de Pessoas Jurídicas (CNPJ). A longa série histórica de patentes e marcas ameniza questões de causalidade reversa, discutida anteriormente. As informações financeiras das empresas foram obtidas junto ao sistema Economática e as variáveis macroeconômicas foram coletadas no Instituto de Pesquisa Econômica Aplicada (IPEA).

Para alguns períodos, não foi possível recuperar a informação para todas as variáveis de algumas empresas. Para evitar perder toda a informação dessas firmas e também eliminar o viés de sobrevivência, optou-se por trabalhar com um painel desbalanceado. O teste de robustez de Verbeek \& Nijman (1992) sugere que a amostra utilizada não sofre do viés de seleção.

\subsection{Operacionalização das variáveis}

\section{Q de Tobin}

A variável dependente do modelo é o logaritmo natural do Q de Tobin, operacionalizado pela relação entre o valor de mercado percebido das firmas e o

\footnotetext{
${ }^{5}$ Os setores de administração de empresas e empreendimentos, bancos e assemelhados, fundos, trustes e outros investimentos, seguradoras e corretoras não foram incluídos devido ao plano de contas contábil ser diferente para esses setores.
} 
valor contábil reconhecido da firma. A escolha do Q de Tobin se baseou nos trabalhos de Griliches (1981), Megna \& Klock (1993), Nagaoka (2006), Sandner \& Block (2011) e Teh et al. (2008).

\section{Ativos Intangíveis}

Visando utilizar uma definição de capital intangível abrangente, esse trabalho considera quatro conceitos, que juntos contabilizam grande parcela ou todo o capital intangível das firmas: quantidade de patentes depositada; estoque de marcas; fluxo de investimento em capital intangível, exceto patentes e marcas; e o nível de intangibilidade $(G I)$ da firma utilizando a definição de ativo intangível de acordo com regras contábeis brasileiras.

A variável de fluxo de investimento em intangível, Fint $g_{i t}$, foi definida como a diferença entre o investimento atual em intangível, Int $_{i t}$, e uma proporção do acúmulo de gastos com intangível do período imediatamente anterior, $\operatorname{In} t g_{i t-1}^{\text {Estoque }}$. Essa variável é calculada pela soma do ativo intangível e diferido das empresas. O histórico dos gastos com intangível e diferido de cada empresa foi usado para calcular o capital intangível a partir do ano de 2000 e foi utilizada uma taxa de depreciação de $15 \%$ ao ano.

$$
\text { Fintg }_{i t}=\operatorname{Intg}_{\text {it }}-(1-0,15) \operatorname{Intg}_{\text {it }-1}^{\text {Estoque }}
$$

A variável quantidade de patentes, $Q p a t_{i t}$, foi calculada por um procedimento semelhante ao fluxo de intangíveis. Na ausência de uma estimativa da taxa de depreciação $(\pi)$ para as inovações patenteadas brasileiras, foram utilizadas duas taxas estimadas para a economia americana: $15 \%$, como em Hall et al. (2005), e 30\%, como Cockburn \& Griliches (1987). Foram contabilizados todos os depósitos de patentes constantes no INPI para cada empresa a partir do ano de 1900:

$$
\text { Qpat }_{i t}=\text { Pat }_{i t}-(1-\pi) P a t_{i t-1}^{\text {Estoque }}
$$

em que Pat $t_{i t-1}^{\text {Estoque }}$ representa o estoque antecedente de depósitos de patentes, depreciado em $\pi$, e Pat ${ }_{i t}$, a quantidade de depósito de patentes anual.

Para o estoque de marcas, Qmarcas $_{i t}$, não é comum utilizar nenhuma taxa de depreciação, pelo contrário, a marca tende a se apreciar com o tempo. Por isso, utilizou-se o estoque de marcas da empresa $i$ no período $t$. A série histórica dessa variável começa em 1909. A vantagem da utilização de longas séries históricas para o estoque de patentes e marcas é que isso torna a endogeneidade do modelo menos provável. As variáveis descritas nessa seção foram submetidas à transformação logarítmica para uso na regressão. No caso de empresas com nenhuma patente, procedeu-se ao artifício de usar $\ln [1+$ quantidade de patentes ou marcas], a fim de evitar perda de informações.

\section{Variáveis de Controle}

Variáveis de controle incluem os fatores ou características latentes das empresas que também impactam o valor da firma por meio de componentes tangíveis. Foram gerados cinco conjuntos de fatores das firmas com três, quatro, cinco e seis elementos para testes de robustez. 
Para controlar pelo ambiente macroeconômico, foram gerados fatores a partir das variáveis: variação do câmbio, taxa de inflação, taxa de desemprego, crescimento do PIB e da taxa básica de juros (Selic). Foram gerados cinco conjuntos de fatores das firmas com três, quatro, cinco e seis elementos para testes de robustez. Detalhes sobre as variáveis primitivas e a operacionalização dos fatores das firmas e macroeconômicos estão no Apêndice.

\section{Resultados}

\subsection{Análise descritiva}

A Tabela 3 apresenta as estatísticas descritivas para o Q de Tobin e para os diferentes conceitos de capital intangível das empresas ${ }^{6}$. O valor médio do Q de Tobin é de 0,736 , ou seja, em média, o valor de mercado das empresas não excede o valor contábil das empresas da amostra. A título de comparação, Kanwar \& Hall (2015) encontra o valor de 4,4 para firmas indianas entre 2001 e 2010.

A quantidade média do estoque de marcas e patentes é, respectivamente, 1,22 e 1,18 , porque muitas firmas não apresentam patentes ( $43,8 \%$ do total) ou marcas $(32,2 \%$ do total). O número máximo de patentes e marcas da amostra é, respectivamente, 269 e 348 . A média do fluxo de investimentos em intangíveis é 1,00, mostrando que ainda são poucas as empresas que investem em ativos intangíveis no Brasil em cada ano. O grau de intangibilidade médio das empresas também é muito próximo de zero.

Tabela 2: Variáveis descritivas

\begin{tabular}{lcccr}
\hline Variável & Média & Desvio, Padrão & Mínimo & Máximo \\
\hline Q de Tobin (q) & 0,736 & 1,030 & 0,000 & 17,118 \\
Estoque de marcas (Qmarcas) & 1,219 & 2,307 & 0,000 & 348,000 \\
Estoque de patentes (Qpat) & 1,177 & 2,131 & 0,000 & 269,413 \\
Fluxo de intangíveis (Fintg)* & 0,999 & 1,047 & 0,041 & 1,172 \\
Grau de intangibilidade (GI) & 0,000 & 0,006 & 0,000 & 0,313 \\
Grau de tangibilidade (T) & 0,310 & 0,246 & 0,000 & 0,972 \\
\hline Nota: 5587 observações, 205 firmas e 46 setores de Janeiro 2000 a Dezembro \\
2014. \\
* Valores em milhões de reais. \\
Fonte: Os autores utilizando o software Stata 14.
\end{tabular}

Analisando cinco dos setores com maiores e menores Q de Tobin, em média, pode-se observar que há correlação positiva entre o estoque de marcas e o valor da empresa (Tabela 4). Entre os maiores Q de Tobin, a média de marcas por empresa está acima da média total, enquanto que a quantidade de patentes apresenta grande heterogeneidade entre os setores. Essa relação não é tão clara para os setores com menores Q de Tobin. Observa-se também uma relação positiva entre o estoque de marcas e patentes, assim como sugerido pela teoria.

Um problema que poderia surgir é a alta correlação entre as variáveis independentes relativas ao intangível, o que inflaria o erro-padrão, enviesando

\footnotetext{
${ }^{6}$ Como teste de robustez, foram utilizadas duas taxas de depreciação do estoque de patentes, $15 \%$ como em Hall et al. (2005) e 30\% como em Cockburn \& Griliches (1987). Como os resultados são muito semelhantes, só serão apresentados aqueles utilizando a taxa de $15 \%$. Os resultados utilizando $30 \%$ estão disponíveis sob pedido.
} 
Tabela 3: Características dos setores

\begin{tabular}{|c|c|c|c|c|c|c|}
\hline Setores econômicos & Obs & $\begin{array}{c}\% \text { de } \\
\text { empresas }\end{array}$ & $\begin{array}{c}\mathrm{N}^{\circ} \text { de } \\
\text { empresas }\end{array}$ & $\begin{array}{l}\text { Q de } \\
\text { Tobin }\end{array}$ & $\begin{array}{l}\text { Estoque } \\
\text { de marcas }\end{array}$ & $\begin{array}{c}\text { Estoque } \\
\text { de patentes }\end{array}$ \\
\hline \multicolumn{7}{|c|}{ Maiores Q de Tobin, em média } \\
\hline Comércio atacadista de bens não duráveis & 44 & 0,395 & 2 & 4,516 & 6,717 & 6,515 \\
\hline Indústria de bebidas e fumo & 64 & 0,574 & 2 & 2,551 & 9,186 & 10,951 \\
\hline Serviços ambulatoriais de saúde & 32 & 0,287 & 2 & 2,035 & 5,170 & 0,088 \\
\hline Editoras de software, jornais, livros e base de dados & 53 & 0,476 & 2 & 1,733 & 5,530 & 0,210 \\
\hline Mineração (exceto petróleo e gás) & 52 & 0,467 & 2 & 1,397 & 6,150 & 25,452 \\
\hline \multicolumn{7}{|c|}{ Menores $Q$ de Tobin, em média } \\
\hline Indústria de produtos de minerais não metálicos & 114 & 1,023 & 4 & 0,377 & 1,422 & 0,969 \\
\hline Indústria de artigos de madeira & 45 & 0,404 & 1 & 0,241 & 5,393 & 4,297 \\
\hline Indústria de fios e tecidos & 227 & 2,037 & 7 & 0,181 & 0,961 & 0,035 \\
\hline Loja de veículos motorizados e peças & 92 & 0,825 & 3 & 0,148 & 0,070 & 0,137 \\
\hline Indústria de produtos de plástico e borracha & 25 & 0,224 & 1 & 0,065 & 2,761 & 2,401 \\
\hline
\end{tabular}


a inferência estatística dos resultados. A fim de explorar a possível relação entre os conceitos de capital intangível aplicados nesse trabalho, calcula-se a matriz de correlação (Tabela 5). Com exceção da correlação de 0,41 entre o estoque de patentes e o estoque de marcas, nenhum coeficiente de correlação é maior do que 0,2. Essa correlação mais elevada entre patentes e marcas é um indício de que, em geral, algumas empresas criam novas marcas para comercializar suas novas tecnologias patenteadas. Devido à baixa correlação entre as variáveis, não se espera que existam problemas de multicolinearidade nas estimações econométricas e acredita-se que a inclusão dessas variáveis represente o capital intangível das firmas, agregando valor ao presente trabalho.

Tabela 4: Matriz de correlação

\begin{tabular}{lrrrrrr}
\hline & Q de Tobin & Qmarcas & Qpat & Fintg & GI & T \\
\hline Q de Tobin & 1,000 & & & & & \\
Qmarcas & 0,155 & 1,000 & & & & \\
Qpat & 0,132 & 0,411 & 1,000 & & & \\
Fintg & 0,012 & 0,012 & $-0,006$ & 1,000 & & \\
GI & $-0,027$ & $-0,026$ & $-0,023$ & 0,095 & 1,000 & \\
T & $-0,190$ & $-0,073$ & $-0,034$ & $-0,022$ & 0,044 & 1,000 \\
\hline
\end{tabular}

\subsection{Resultados econométricos}

Apresenta-se nessa seção os resultados econométricos para as duas estratégias discutidas na metodologia para lidar com o problema da endogeneidade. Inicialmente, aplicam-se os métodos mínimos quadrados agrupados (MQA) e efeitos fixos (EF) para estimar a Equação (5), cujos resultados são apresentados nas Tabelas 6 e 7, respectivamente. Após, utiliza-se o system GMM para estimar as Equações (6) e (7), mostrados na Tabela A. $1^{7}$.

A estimativa por MQA na Tabela 6 mostra que os efeitos do estoque de marcas nos diferentes modelos são positivos e significativos, colunas 1, 5, 6 e 10 . Seu valor é estável entre as estimações, sendo ligeiramente menor quando controlado pelas dummies de ano. O estoque de patentes apresenta elasticidade muito próxima de zero e não é significativa. O fluxo de intangíveis é significativo a $10 \%$ em todas as estimações. Para o grau de intangibilidade, o sinal negativo é mantido com a inclusão das dummies, mas a magnitude fica menor e o coeficiente passa a ser significativo. A parte final da tabela, entretanto, mostra que esse modelo sofre de heterocedasticidade. Corroborando a expectativa criada pela Tabela 5 que a multicolinearidade não seria um problema, todas as estatísticas de VIF's estão abaixo de 4.

$\mathrm{Na}$ existência de efeitos fixos das empresas, as estimativas por MQA estariam enviesadas. Para eliminar esse viés, emprega-se os métodos de efeitos aleatórios ou efeitos fixos. O teste de Hausman, ao final da Tabela 7, rejeita a hipótese nula de que os efeitos fixos das firmas não são correlacionados com as variáveis explicativas, indicando que a melhor maneira de estimar os parâmetros de interesse é por meio do método de efeitos fixos. Como os resíduos

\footnotetext{
${ }^{7}$ Devido à semelhança dos resultados entre as estimações com MQA, EF e system GMM, só são mostradas as estimativas com cinco fatores específicos das firmas e um fator macroeconômico. Os resultados para os outros conjuntos de fatores macroeconômicos e específicos das firmas estão disponíveis sob pedido.
} 
Tabela 5: Determinantes do Q de Tobin de companhias abertas com métodos de mínimos quadrados agrupados

\begin{tabular}{|c|c|c|c|c|c|c|c|c|c|c|}
\hline Variáveis explicativas & (1) & (2) & (3) & $(4)$ & (5) & $(6)$ & (7) & (8) & (9) & (10) \\
\hline Estoque de marcas & $\begin{array}{l}0,044^{* * *} \\
{[3,6287]}\end{array}$ & & & & $\begin{array}{l}0,043^{* * *} \\
{[3,442]}\end{array}$ & $\begin{array}{l}0,042^{* * *} \\
{[3,628]}\end{array}$ & & & & $\begin{array}{l}0,041^{* * *} \\
{[3,351]}\end{array}$ \\
\hline Estoque de patentes & & $\begin{array}{r}0,0121 \\
{[0,933]}\end{array}$ & & & $\begin{array}{c}-0,001 \\
{[-0,111]}\end{array}$ & & $\begin{array}{l}0,014 \\
{[1,171]}\end{array}$ & & & $\begin{array}{l}0,001 \\
{[0,122]}\end{array}$ \\
\hline Fluxo de intangíveis & & & $\begin{array}{l}0,456^{*} \\
{[1,6488]}\end{array}$ & & $\begin{array}{c}0,471^{*} \\
{[1,699]}\end{array}$ & & & $\begin{array}{l}0,459^{*} \\
{[1,710]}\end{array}$ & & $\begin{array}{l}0,498^{*} \\
{[1,852]}\end{array}$ \\
\hline Ln(Ativo intangível) & & & & $\begin{array}{l}-5,543^{*} \\
{[-1,7517]}\end{array}$ & $\begin{array}{r}-5,779^{*} \\
{[-1,821]}\end{array}$ & & & & $\begin{array}{c}-8,662^{* * *} \\
{[-2,818]}\end{array}$ & $\begin{array}{c}-8,908^{* * * *} \\
{[-2,891]}\end{array}$ \\
\hline Ln(Ativo tangível) & $\begin{array}{c}-0,711^{* * *} \\
{[-12,558]}\end{array}$ & $\begin{array}{c}-0,725^{* * *} \\
{[-12,800]}\end{array}$ & $\begin{array}{c}-0,727^{* * *} \\
{[-12,890]}\end{array}$ & $\begin{array}{c}-0,725^{* * * *} \\
{[-12,836]}\end{array}$ & $\begin{array}{c}-0,704^{* * * *} \\
{[-12,406]}\end{array}$ & $\begin{array}{c}-0,679^{* * *} \\
{[-12,253]}\end{array}$ & $\begin{array}{c}-0,690^{* * *} \\
{[-12,500]}\end{array}$ & $\begin{array}{c}-0,697^{* * *} \\
{[-12,605]}\end{array}$ & $-0,691^{* * *}$ & $\begin{array}{c}-0,669^{* * * *} \\
{[-12,035]}\end{array}$ \\
\hline Fator 1: Tamanho da firma & $\begin{array}{l}0,220^{* * *} \\
{[15,060]}\end{array}$ & $\begin{array}{l}0,234^{* * *} \\
{[15,402]}\end{array}$ & $\begin{array}{l}0,241^{* * *} \\
{[17,914]}\end{array}$ & $\begin{array}{l}0,241^{* * *} \\
{[17,872]}\end{array}$ & $\begin{array}{l}0,222^{* * * *} \\
{[14,127]}\end{array}$ & $\begin{array}{l}0,202^{* * * *} \\
{[14,156]}\end{array}$ & $\begin{array}{l}0,215^{* * * *} \\
{[14,447]}\end{array}$ & $\begin{array}{l}0,223^{* * *} \\
{[16,929]}\end{array}$ & $\begin{array}{l}0,223^{\text {**** }} \\
{[16,883]}\end{array}$ & $\begin{array}{l}0,203^{\text {**** }} \\
{[13,222]}\end{array}$ \\
\hline Fator 2: Liquidez & $\begin{array}{l}0,079^{* * * *} \\
{[5,771]}\end{array}$ & $\begin{array}{l}0,088^{* * *} \\
{[6,460]}\end{array}$ & $\begin{array}{l}0,089^{* * *} \\
{[6,554]}\end{array}$ & $\begin{array}{l}0,088^{* * * *} \\
{[6,480]}\end{array}$ & $\begin{array}{l}0,079^{* * * *} \\
{[5,768]}\end{array}$ & $\begin{array}{l}0,071^{* * *} \\
{[5,344]}\end{array}$ & $\begin{array}{l}0,079^{* * *} \\
{[5,987]}\end{array}$ & $\begin{array}{l}0,080^{* * *} \\
{[6,092]}\end{array}$ & $\begin{array}{l}0,079^{* * * *} \\
{[5,990]}\end{array}$ & $\begin{array}{l}0,071^{* * *} \\
{[5,322]}\end{array}$ \\
\hline Fator 3: Retorno do acionista & $\begin{array}{l}0,041^{* * * *} \\
{[2,986]}\end{array}$ & $\begin{array}{l}0,042^{* * *} \\
{[2,986]}\end{array}$ & $\begin{array}{c}0,0421^{* * *} \\
{[2,997]}\end{array}$ & $\begin{array}{c}0,0421^{* * *} \\
{[2,995]}\end{array}$ & $\begin{array}{l}0,041^{* * * *} \\
{[2,980]}\end{array}$ & $\begin{array}{l}0,039^{* * * *} \\
{[2,876]}\end{array}$ & $\begin{array}{l}0,039^{* * * *} \\
{[2,880]}\end{array}$ & $\begin{array}{l}0,039^{* * *} \\
{[2,895]}\end{array}$ & $\begin{array}{l}0,039^{* * * *} \\
{[2,890]}\end{array}$ & $\begin{array}{l}0,038^{* * * *} \\
{[2,860]}\end{array}$ \\
\hline Fator 4: Risco & $\begin{array}{l}0,098^{* * * *} \\
{[7,333]}\end{array}$ & $\begin{array}{l}0,099^{* * *} \\
{[7,367]}\end{array}$ & $\begin{array}{l}0,099^{* * * *} \\
{[7,404]}\end{array}$ & $\begin{array}{l}0,099^{* * * *} \\
{[7,373]}\end{array}$ & $\begin{array}{l}0,098^{* * * *} \\
{[7,355]}\end{array}$ & $\begin{array}{l}0,092^{* * * *} \\
{[7,067]}\end{array}$ & $\begin{array}{l}0,093^{* * *} \\
{[7,095]}\end{array}$ & $\begin{array}{l}0,093^{* * * *} \\
{[7,134]}\end{array}$ & $\begin{array}{l}0,093^{* * * *} \\
{[7,093]}\end{array}$ & $\begin{array}{l}0,092^{* * * *} \\
{[7,075]}\end{array}$ \\
\hline Fator 5: Singularidades & $\begin{array}{l}0,063^{* * * *} \\
{[3,544]}\end{array}$ & $\begin{array}{l}0,067^{* * *} \\
{[3,729]}\end{array}$ & $\begin{array}{l}0,068^{* * *} \\
{[3,800]}\end{array}$ & $\begin{array}{l}0,068^{* * *} \\
{[3,793]}\end{array}$ & $\begin{array}{l}0,063^{* * *} \\
{[3,552]}\end{array}$ & $\begin{array}{l}0,059^{* * * *} \\
{[3,384]}\end{array}$ & $\begin{array}{l}0,062^{* * * *} \\
{[3,552]}\end{array}$ & $\begin{array}{l}0,063^{* * * *} \\
{[3,636]}\end{array}$ & $\begin{array}{l}0,063^{* * * *} \\
{[3,627]}\end{array}$ & $\begin{array}{l}0,058^{* * * *} \\
{[3,381]}\end{array}$ \\
\hline Constante & $\begin{array}{l}0,983^{* * * *} \\
{[39,919]}\end{array}$ & $\begin{array}{l}1,013^{* * * *} \\
{[40,779]}\end{array}$ & $\begin{array}{l}1,023^{* * * *} \\
{[46,469]}\end{array}$ & $\begin{array}{l}1,023^{* * *} \\
{[46,469]}\end{array}$ & $\begin{array}{l}0,985^{* * * *} \\
{[37,680]}\end{array}$ & $\begin{array}{l}0,616^{* * * *} \\
{[8,021]}\end{array}$ & $\begin{array}{l}0,652^{* * * *} \\
{[8,494]}\end{array}$ & $\begin{array}{l}0,665^{* * * *} \\
{[8,784]}\end{array}$ & $\begin{array}{l}0,664^{* * * *} \\
{[8,777]}\end{array}$ & $\begin{array}{l}0,612^{* * * *} \\
{[7,918]}\end{array}$ \\
\hline Dummy de ano & Não & Não & Não & Não & Não & Sim & Sim & Sim & Sim & Sim \\
\hline$R^{2}$ & 0,153 & 0,151 & 0,151 & 0,151 & 0,154 & 0,207 & 0,205 & 0,205 & 0,206 & 0,209 \\
\hline Teste de Heterocedasticidade & $832,240^{* * *}$ & $821,150^{* * * *}$ & $818,450^{* * *}$ & $820,250^{* * *}$ & $833,480^{* * * *}$ & $1516,300^{* * *}$ & $1511,600^{* * *}$ & $1502,800^{* * * *}$ & $1507,200^{* * *}$ & $1519,100^{* * *}$ \\
\hline VIF & 1,093 & 1,108 & 1,034 & 1,035 & 1,133 & 3,191 & 3,194 & 3,167 & 3,167 & 2,958 \\
\hline Teste de significância conjunta & $118,150^{* * *}$ & $116,340^{* * * *}$ & $116,610^{* * *}$ & $116,660^{* * *}$ & $86,496^{* * *}$ & $62,044^{* * *}$ & $61,370^{* * *}$ & $61,459^{* * *}$ & $61,746^{* * *}$ & $55,123^{* * *}$ \\
\hline
\end{tabular}


das estimativas de efeitos fixos são heterocedásticos, sendo que as variâncias variam entre as firmas, mas são constantes no tempo, segundo o teste de Wald, e autocorrelacionados, segundo o teste de Wooldridge (2010), calculam-se os erros-padrões robustos a heterocedasticidade e autocorrelação.

Os resultados para o estoque de marcas são semelhantes aos encontrados anteriormente. Essa conta do ativo intangível continua mostrando efeitos positivos e significativos (colunas 11, 15, 16 e 20 da Tabela 7), corroborando os trabalhos de Teh et al. (2008), Oliveira et al. (2010) e Sandner \& Block (2011). Com base na coluna 20 (Tabela 7), pode-se afirmar que um aumento de $1 \%$ no estoque de marcas aumenta o $\mathrm{Q}$ de Tobin em 0,036\%.

O estoque de patentes, fluxo de intangíveis e grau de intangibilidade não mostraram resultados conclusivos. O estoque de patentes mantém o sinal negativo em todas as estimações (colunas 12, 15, 17 e 20) e os coeficientes dos modelos com a inclusão das dummies de ano são significativos. O oposto acontece com o fluxo de intangíveis. Ele tem o efeito estimado positivo em todas as especificações, mas com a inclusão das variáveis binárias, ele perde a sua significância. Já o grau de intangibilidade, apesar de manter a significância em todas as estimações, inverte o sinal entre os modelos sem e com as variáveis dummies.

Como discutido na metodologia, a estratégia de defasar as covariadas implica em um modelo estático e se perde o efeito contemporâneo entre as variáveis. O system GMM consegue lidar com essas duas limitações. Além de permitir a estimação do efeito contemporâneo do ativo intangível no Q de Tobin, a inclusão da parte autorregressiva também permite estruturas mais complexas de defasagens das covariadas.

Os resultados da estimação por system GMM estão na Tabela A.1. Encontrase que, entre as quatro medidas de intangíveis utilizadas, somente o fluxo de intangíveis é significativo (colunas 23, 25, 28 e 30). Observa-se a diminuição de significância entre as estimações com e sem dummies de tempo. Na ausência das variáveis binárias, o fluxo de intangíveis é significativo a $1 \%$, mas a inclusão dessas variáveis faz com que ele seja significativo a $10 \%$ na especificação da coluna 28 e $5 \%$ na coluna 30 . Sua magnitude também se manteve estável em torno de 0,20 . Argumenta-se que esse resultado pode ser um indicativo de que o mercado valoriza, ainda que com certa apreensão, o investimento em intangíveis. Diz-se apreensão, pois o grau de intangibilidade, de forma oposta às estimações prévias, não apresentou nenhum coeficiente significativo (colunas 24, 25, 29 e 30), assim como encontrado por Kayo et al. (2009). Interpretando conjuntamente o resultado para essas duas variáveis, sugere-se que investidores julgam com receio a estocagem de ativos intangíveis, talvez em função do aumento do risco associado a tal prática ou da opacidade desses gastos como 'ativos'. Entretanto, o mercado deve valorizar os investimentos em intangíveis para, por exemplo, a manutenção da competitividade, reposição do capital ou outros objetivos considerados de baixo risco.

O estoque de marcas não foi significativo por esse método em nenhuma das estimações (colunas 21, 25, 26 e 30). Comparando esse resultado com o anterior, sugere-se que esse ativo tenha um efeito defasado sobre o valor da empresa. Uma possível explicação é que investidores avessos ao risco podem evitar investir em novas marcas até que eles tenham mais segurança de que ela irá se estabelecer no mercado com sucesso. Assim, a defasagem do efeito do estoque de marcas no valor da empresa é uma consequência da própria incerteza inerente nesse tipo de ativo. 
Tabela 6: Determinantes do Q de Tobin de companhias abertas com métodos de efeitos fixos robustos

\begin{tabular}{|c|c|c|c|c|c|c|c|c|c|c|}
\hline Variáveis explicativas & (11) & (12) & (13) & (14) & (15) & (16) & (17) & (18) & (19) & $(20)$ \\
\hline Estoque de marcas & $\begin{array}{l}0,043^{* *} \\
{[2,137]}\end{array}$ & & & & $\begin{array}{l}0,043^{* *} \\
{[2,088]}\end{array}$ & $\begin{array}{l}0,037^{* *} \\
{[2,098]}\end{array}$ & & & & $\begin{array}{l}0,036^{* *} \\
{[2,037]}\end{array}$ \\
\hline Estoque de patentes & & $\begin{array}{c}-0,076 \\
{[-1,017]}\end{array}$ & & & $\begin{array}{c}-0,074 \\
{[-0,977]}\end{array}$ & & $\begin{array}{r}-0,132^{*} \\
{[-1,901]}\end{array}$ & & & $\begin{array}{c}-0,131^{*} \\
{[-1,870]}\end{array}$ \\
\hline Fluxo de intangíveis & & & $\begin{array}{l}0,076^{* * * *} \\
{[5,183]}\end{array}$ & & $\begin{array}{l}0,061^{* * *} \\
{[6,306]}\end{array}$ & & & $\begin{array}{l}0,021 \\
{[1,078]}\end{array}$ & & $\begin{array}{l}0,026^{*} \\
{[1,863]}\end{array}$ \\
\hline Ln(Ativo intangível) & & & & $\begin{array}{l}2,347^{* * *} \\
{[2,719]}\end{array}$ & $\begin{array}{l}2,274^{* * *} \\
{[2,620]}\end{array}$ & & & & $\begin{array}{c}-2,141^{* * *} \\
{[-2,667]}\end{array}$ & $\begin{array}{c}-2,103^{* * * *} \\
{[-2,635]}\end{array}$ \\
\hline Ln(Ativo tangível) & $\begin{array}{r}-0,590^{* *} \\
{[-2,271]}\end{array}$ & $\begin{array}{r}-0,586^{* *} \\
{[-2,266]}\end{array}$ & $\begin{array}{r}-0,589^{* *} \\
{[-2,291]}\end{array}$ & $\begin{array}{r}-0,590^{* * *} \\
{[-2,293]}\end{array}$ & $\begin{array}{r}-0,588^{* * *} \\
{[-2,249]}\end{array}$ & $\begin{array}{c}-0,365 \\
{[-1,525]}\end{array}$ & $\begin{array}{c}-0,348 \\
{[-1,457]}\end{array}$ & $\begin{array}{c}-0,370 \\
{[-1,546]}\end{array}$ & $\begin{array}{c}-0,369 \\
{[-1,541]}\end{array}$ & $\begin{array}{c}-0,343 \\
{[-1,432]}\end{array}$ \\
\hline Fator 1: Tamanho da firma & $\begin{array}{l}0,239^{* *} \\
{[2,057]}\end{array}$ & $\begin{array}{l}0,258^{* *} \\
{[2,175]}\end{array}$ & $\begin{array}{l}0,250^{* * *} \\
{[2,147]}\end{array}$ & $\begin{array}{l}0,251^{* *} \\
{[2,155]}\end{array}$ & $\begin{array}{l}0,249^{* *} \\
{[2,095]}\end{array}$ & $\begin{array}{l}0,130 \\
{[1,098]}\end{array}$ & $\begin{array}{l}0,148 \\
{[1,228]}\end{array}$ & $\begin{array}{l}0,144 \\
{[1,207]}\end{array}$ & $\begin{array}{l}0,142 \\
{[1,194]}\end{array}$ & $\begin{array}{l}0,134 \\
{[1,111]}\end{array}$ \\
\hline Fator 2: Liquidez & $\begin{array}{l}0,078 \\
{[1,343]}\end{array}$ & $\begin{array}{l}0,073 \\
{[1,230]}\end{array}$ & $\begin{array}{l}0,075 \\
{[1,273]}\end{array}$ & $\begin{array}{l}0,075 \\
{[1,268]}\end{array}$ & $\begin{array}{l}0,076 \\
{[1,297]}\end{array}$ & $\begin{array}{l}0,075 \\
{[1,122]}\end{array}$ & $\begin{array}{l}0,070 \\
{[1,029]}\end{array}$ & $\begin{array}{l}0,070 \\
{[1,039]}\end{array}$ & $\begin{array}{l}0,070 \\
{[1,039]}\end{array}$ & $\begin{array}{l}0,074 \\
{[1,109]}\end{array}$ \\
\hline Fator 3: Retorno do acionista & $\begin{array}{l}0,007 \\
{[0,800]}\end{array}$ & $\begin{array}{l}0,008 \\
{[0,944]}\end{array}$ & $\begin{array}{l}0,008 \\
{[0,951]}\end{array}$ & $\begin{array}{l}0,008 \\
{[0,954]}\end{array}$ & $\begin{array}{l}0,007 \\
{[0,800]}\end{array}$ & $\begin{array}{l}0,005 \\
{[0,618]}\end{array}$ & $\begin{array}{l}0,006 \\
{[0,707]}\end{array}$ & $\begin{array}{l}0,007 \\
{[0,753]}\end{array}$ & $\begin{array}{l}0,007 \\
{[0,751]}\end{array}$ & $\begin{array}{l}0,005 \\
{[0,578]}\end{array}$ \\
\hline Fator 4: Risco & $\begin{array}{l}0,025^{* *} \\
{[2,044]}\end{array}$ & $\begin{array}{l}0,026^{* *} \\
{[2,079]}\end{array}$ & $\begin{array}{l}0,026^{* *} \\
{[2,097]}\end{array}$ & $\begin{array}{l}0,026^{* *} \\
{[2,098]}\end{array}$ & $\begin{array}{l}0,025^{* * *} \\
{[2,036]}\end{array}$ & $\begin{array}{l}0,018 \\
{[1,603]}\end{array}$ & $\begin{array}{l}0,018 \\
{[1,606]}\end{array}$ & $\begin{array}{l}0,018^{*} \\
{[1,660]}\end{array}$ & $\begin{array}{l}0,019 \\
{[1,651]}\end{array}$ & $\begin{array}{l}0,018 \\
{[1,546]}\end{array}$ \\
\hline Fator 5: Singularidades & $\begin{array}{l}0,029^{* *} \\
{[2,437]}\end{array}$ & $\begin{array}{l}0,031^{* * *} \\
{[2,631]}\end{array}$ & $\begin{array}{l}0,030^{* * * *} \\
{[2,601]}\end{array}$ & $\begin{array}{l}0,030^{* * * *} \\
{[2,608]}\end{array}$ & $\begin{array}{l}0,030^{* * *} \\
{[2,475]}\end{array}$ & $\begin{array}{l}0,022^{* *} \\
{[2,476]}\end{array}$ & $\begin{array}{l}0,024^{* *} \\
{[2,560]}\end{array}$ & $\begin{array}{l}0,023^{* * *} \\
{[2,644]}\end{array}$ & $\begin{array}{l}0,023^{* * *} \\
{[2,634]}\end{array}$ & $\begin{array}{l}0,023^{* *} \\
{[2,405]}\end{array}$ \\
\hline Fator macroeconômico único & $\begin{array}{c}-0,156^{* * * *} \\
{[-8,727]}\end{array}$ & $\begin{array}{c}-0,158^{* * *} \\
{[-8,660]}\end{array}$ & $\begin{array}{c}-0,155^{* * *} \\
{[-8,674]}\end{array}$ & $\begin{array}{c}-0,155^{* * * *} \\
{[-8,670]}\end{array}$ & $\begin{array}{c}-0,159^{* * * *} \\
{[-8,712]}\end{array}$ & $\begin{array}{c}-0,034 \\
{[-1,597]}\end{array}$ & $\begin{array}{c}-0,034 \\
{[-1,566]}\end{array}$ & $\begin{array}{c}-0,035 \\
{[-1,612]}\end{array}$ & $\begin{array}{c}-0,035 \\
{[-1,620]}\end{array}$ & $\begin{array}{c}-0,033 \\
{[-1,548]}\end{array}$ \\
\hline Constante & $\begin{array}{l}0,934^{* * * *} \\
{[10,870]}\end{array}$ & $\begin{array}{l}1,028^{* * * *} \\
{[9,596]}\end{array}$ & $\begin{array}{l}0,968^{* * * *} \\
{[11,782]}\end{array}$ & $\begin{array}{l}0,968^{* * * *} \\
{[11,774]}\end{array}$ & $\begin{array}{l}0,992^{* * * *} \\
{[8,904]}\end{array}$ & $\begin{array}{l}0,572^{* * *} \\
{[5,235]}\end{array}$ & $\begin{array}{l}0,691^{* * *} \\
{[5,799]}\end{array}$ & $\begin{array}{l}0,608^{* * *} \\
{[5,718]}\end{array}$ & $\begin{array}{l}0,608^{* * *} \\
{[5,716]}\end{array}$ & $\begin{array}{l}0,654^{* * *} \\
{[5,341]}\end{array}$ \\
\hline Dummy de ano & Não & Não & Não & Não & Não & Sim & Sim & Sim & Sim & Sim \\
\hline$R^{2}$ overal & 0,143 & 0,134 & 0,142 & 0,141 & 0,138 & 0,195 & 0,148 & 0,193 & 0,194 & 0,157 \\
\hline$R^{2}$ between & 0,176 & 0,171 & 0,179 & 0,177 & 0,171 & 0,245 & 0,181 & 0,249 & 0,251 & 0,193 \\
\hline$R^{2}$ within & 0,075 & 0,074 & 0,073 & 0,073 & 0,076 & 0,171 & 0,172 & 0,170 & 0,170 & 0,174 \\
\hline Teste de Hausman & $23,039^{* * *}$ & $25,286^{* * *}$ & $24,477^{* * *}$ & $24,387^{* * *}$ & $27,744^{* * *}$ & $48,443^{* * *}$ & $57,197^{* * *}$ & $52,243^{* * *}$ & $49,011^{* * *}$ & $58,827^{* * *}$ \\
\hline Teste de Nijman e Verbeek & 1,405 & 1,383 & 1,359 & 1,359 & 1,437 & 0,327 & 0,338 & 0,317 & 0,308 & 0,333 \\
\hline Teste de autocorrelação & $65,940^{* * *}$ & $65,980^{* * *}$ & $65,940^{* * *}$ & $65,910^{* * *}$ & $65,950^{* * *}$ & $71,000^{* * *}$ & $71,050^{* * *}$ & $71,000^{* * *}$ & $70,970^{* * *}$ & $71,030^{* * *}$ \\
\hline Teste de heteroscedasticidade ${ }^{1}$ & $4 \times 10^{5^{* * *}}$ & $4 \times 10^{5^{* * *}}$ & $4 \times 10^{5^{* * *}}$ & $4 \times 10^{5^{* * *}}$ & $3 \times 10^{5^{* * *}}$ & $8 \times 10^{6^{* * *}}$ & $9 \times 10^{5^{* * *}}$ & $8 \times 10^{6^{* * *}}$ & $7 \times 10^{6^{* * *}}$ & $6 \times 10^{5^{* * *}}$ \\
\hline
\end{tabular}

Notas: Estatísticas $t$ em colchetes, ${ }^{*} p<0,1,{ }^{* *} p<0,05,{ }^{* * *} p<0,01$. Todas as variáveis estão defasadas em um período. N=5253 e Número de firmas $=203$.

Todas as estimativas incluem um fator macroeconômico.

Foi utilizado o teste de Wald modificado para heteroscedasticidade em grupo.

Fonte: Os autores utilizando o software Stata 14. 
Para o estoque de patente, o efeito não foi significativo (colunas 22, 25, 27 e 30). Esse resultado corrobora os de Nagaoka (2006), Teh et al. (2008), Oliveira et al. (2010), Sandner \& Block (2011) e Belenzon \& Patacconi (2013) Esse resultado é diferente apenas de Griliches (1981) que utiliza as variáveis de patentes previstas e imprevistas. Apesar de ser um resultado comum na literatura tanto para países desenvolvidos quanto em desenvolvimento, sugerese que a falta de evidência para esse segundo grupo pode ser consequência do processo de inovação das firmas desses países se pautar na imitação e difusão, tendo menor intensidade em desenvolvimento de novas tecnologias (Kanwar \& Hall 2015).

Não se rejeita a hipótese de que existam retornos de escala constante na função valor das firmas. Chega-se a essa conclusão observando o coeficiente não significativo para o grau de tangibilidade. O que se estima na realidade é $\sigma-1$, em que sigma é o parâmetro de retornos de escala.

Apesar de Kanwar \& Hall (2015) argumentar que o passado das firmas não é um bom instrumento para as empresas indianas, o teste de Hansen sugere o oposto para as firmas brasileiras, como pode ser visto na última parte da Tabela A.1. Não se rejeita a hipótese nula de que os instrumentos sejam válidos para nenhuma das estimações. Utiliza-se como instrumentos a segunda e terceira defasagens ${ }^{9}$. Rejeita-se também a hipótese nula de que os resíduos sejam autocorrelacionados. Dessa forma, validam-se as principais hipóteses para a utilização do system GMM.

Portanto, conclui-se que o mercado avalia de maneira diferente as distintas definições de capital intangível das empresas. Investimento em marcas e fluxo de intangíveis têm impactos positivos no valor das firmas. Entretanto, o efeito é ambíguo para o estoque de patentes e grau de intangibilidade. O resultado para essa última variável indica que, seja pela falta de conhecimento sobre a capacidade de realização desse ativo ou pelo seu risco de deterioração em cenários recessivos, ela tem um efeito negativo no valor. O efeito ambíguo da quantidade de patentes parece refletir a ideia de que firmas em países em desenvolvimento têm maior potencial de obter crescimento por meio da imitação e difusão do que via desenvolvimento de novas tecnologias.

\section{Conclusão}

Esse trabalho aplica o modelo de Griliches (1981) para as empresas brasileiras de capital aberto. A criação de valor é medida pelo $\mathrm{Q}$ de Tobin, e esta é uma função dos ativos intangíveis e tangíveis da empresa. Define-se o capital intangível das empresas da forma mais abrangente possível, dada a limitação de informação. Ele é medido de acordo com os estoques de patentes e marcas, fluxo de investimento em intangíveis e grau de intangibilidade da empresa.

Compila-se um painel de 208 firmas representando 46 setores da economia brasileira de 2000 a 2014 listadas na Bolsa de Valores de São Paulo. Os

\footnotetext{
${ }^{8}$ Para empresas americanas somente, pois para empresas europeias, ele encontra um efeito significativo do estoque de patentes de anos anteriores ao da aquisição.

${ }^{9}$ Para testes de robustez, foram utilizados cinco conjuntos de instrumentos: 1) a segunda e terceira defasagens; 2) da segunda a quarta defasagens; 3 ) da segunda a décima defasagens; 4) da segunda a vigésima defasagem; 5) todas as defasagens. São apresentados somente os resultados para o primeiro conjunto devido à semelhança entre os três primeiros. Os dois últimos conjuntos não apresentaram resultados confiáveis devido ao teste de Hansen não ser robusto a grandes quantidades de momentos. Todas as estimações estão disponíveis para verificação sob pedido.
} 
Tabela 7: Determinantes do Q de Tobin de companhias abertas com métodos de system GMM

\begin{tabular}{|c|c|c|c|c|c|c|c|c|c|c|}
\hline Variáveis explicativas & $(21)$ & $(22)$ & $(23)$ & $(24)$ & $(25)$ & $(26)$ & $(27)$ & $(28)$ & $(28)$ & $(30)$ \\
\hline Q de $\operatorname{Tobin}_{t-1}$ & $\begin{array}{l}0,677^{* * * *} \\
{[10,211]}\end{array}$ & $\begin{array}{l}0,683^{* * *} \\
{[10,527]}\end{array}$ & $\begin{array}{l}0,685^{* * *} \\
{[10,360]}\end{array}$ & $\begin{array}{l}0,678^{* * * *} \\
{[10,136]}\end{array}$ & $\begin{array}{l}0,647^{* * *} \\
{[9,7580]}\end{array}$ & $\begin{array}{l}0,626^{* * * *} \\
{[11,630]}\end{array}$ & $\begin{array}{l}0,625^{* * *} \\
{[11,639]}\end{array}$ & $\begin{array}{l}0,630^{* * * *} \\
{[11,834]}\end{array}$ & $\begin{array}{l}0,615^{* * *} \\
{[11,673]}\end{array}$ & $\begin{array}{l}0,598^{* * * *} \\
{[10,668]}\end{array}$ \\
\hline Estoque de marcas $_{t}$ & $\begin{array}{l}0,0214 \\
{[1,1319]}\end{array}$ & & & & $\begin{array}{l}0,018 \\
{[0,997]}\end{array}$ & $\begin{array}{l}0,026 \\
{[1,407]}\end{array}$ & & & & $\begin{array}{l}0,020 \\
{[1,106]}\end{array}$ \\
\hline Estoque de patentes $_{t}$ & & $\begin{array}{l}-0,035 \\
{[-0,3768]}\end{array}$ & & & $\begin{array}{c}-0,046 \\
{[-0,613]}\end{array}$ & & $\begin{array}{l}0,008 \\
{[0,085]}\end{array}$ & & & $\begin{array}{c}-0,005 \\
{[-0,072]}\end{array}$ \\
\hline Fluxo de intangíveis $s_{t}$ & & & $\begin{array}{l}0,197^{* * *} \\
{[2,860]}\end{array}$ & & $\begin{array}{l}0,242^{* * * *} \\
{[3,128]}\end{array}$ & & & $\begin{array}{l}0,140^{*} \\
{[1,904]}\end{array}$ & & $\begin{array}{l}0,207^{* * *} \\
{[2,014]}\end{array}$ \\
\hline $\operatorname{Ln}($ ativo intangível $t)$ & & & & $\begin{array}{c}-0,763 \\
{[-0,313]}\end{array}$ & $\begin{array}{l}0,497 \\
{[0,123]}\end{array}$ & & & & $\begin{array}{c}-3,210 \\
{[-1,338]}\end{array}$ & $\begin{array}{c}-3,594 \\
{[-0,707]}\end{array}$ \\
\hline $\operatorname{Ln}\left(\right.$ ativo tangível $\left.{ }_{t}\right)$ & $\begin{array}{c}-0,056 \\
{[-0,153]}\end{array}$ & $\begin{array}{c}-0,058 \\
{[-0,152]}\end{array}$ & $\begin{array}{c}-0,042 \\
{[-0,109]}\end{array}$ & $\begin{array}{c}-0,191 \\
{[-0,494]}\end{array}$ & $\begin{array}{c}-0,309 \\
{[-1,109]}\end{array}$ & $\begin{array}{l}0,065 \\
{[0,1920]}\end{array}$ & $\begin{array}{l}0,040 \\
{[0,1180]}\end{array}$ & $\begin{array}{l}0,082 \\
{[0,2272]}\end{array}$ & $\begin{array}{c}-0,036 \\
{[-0,097]}\end{array}$ & $\begin{array}{c}-0,229 \\
{[-0,706]}\end{array}$ \\
\hline Fator 1: Tamanho da firma $t$ & $\begin{array}{l}0,282^{* * *} \\
{[2,029]}\end{array}$ & $\begin{array}{l}0,265^{* *} \\
{[2,018]}\end{array}$ & $\begin{array}{l}0,268^{* *} \\
{[2,105]}\end{array}$ & $\begin{array}{l}0,238^{*} \\
{[1,945]}\end{array}$ & $\begin{array}{l}0,112 \\
{[0,940]}\end{array}$ & $\begin{array}{l}0,238^{*} \\
{[1,679]}\end{array}$ & $\begin{array}{l}0,210 \\
{[1,539]}\end{array}$ & $\begin{array}{l}0,225^{*} \\
{[1,743]}\end{array}$ & $\begin{array}{l}0,200 \\
{[1,546]}\end{array}$ & $\begin{array}{l}0,051 \\
{[0,429]}\end{array}$ \\
\hline Fator 2: Liquidez $t$ & $\begin{array}{l}0,070 \\
{[0,587]}\end{array}$ & $\begin{array}{l}0,120 \\
{[1,020]}\end{array}$ & $\begin{array}{l}0,102 \\
{[0,774]}\end{array}$ & $\begin{array}{l}0,130 \\
{[0,963]}\end{array}$ & $\begin{array}{l}0,088 \\
{[0,679]}\end{array}$ & $\begin{array}{l}0,119 \\
{[0,958]}\end{array}$ & $\begin{array}{l}0,172 \\
{[1,357]}\end{array}$ & $\begin{array}{l}0,154 \\
{[1,117]}\end{array}$ & $\begin{array}{l}0,169 \\
{[1,209]}\end{array}$ & $\begin{array}{l}0,125 \\
{[0,846]}\end{array}$ \\
\hline Fator 3: Retorno do acionista $t$ & $\begin{array}{c}-0,029 \\
{[-0,468]}\end{array}$ & $\begin{array}{c}-0,014 \\
{[-0,254]}\end{array}$ & $\begin{array}{c}-0,014 \\
{[-0,240]}\end{array}$ & $\begin{array}{c}-0,001 \\
{[-0,012]}\end{array}$ & $\begin{array}{c}-0,008 \\
{[-0,167]}\end{array}$ & $\begin{array}{l}0,001 \\
{[0,020]}\end{array}$ & $\begin{array}{l}0,027 \\
{[0,491]}\end{array}$ & $\begin{array}{l}0,021 \\
{[0,366]}\end{array}$ & $\begin{array}{l}0,036 \\
{[0,628]}\end{array}$ & $\begin{array}{l}0,044 \\
{[1,107]}\end{array}$ \\
\hline Fator 4: $\mathrm{Risco}_{t}$ & $\begin{array}{l}0,049 \\
{[0,763]}\end{array}$ & $\begin{array}{l}0,059 \\
{[0,953]}\end{array}$ & $\begin{array}{l}0,053 \\
{[0,801]}\end{array}$ & $\begin{array}{l}0,056 \\
{[0,855]}\end{array}$ & $\begin{array}{c}-0,019 \\
{[-0,252]}\end{array}$ & $\begin{array}{l}0,046 \\
{[0,645]}\end{array}$ & $\begin{array}{l}0,062 \\
{[0,851]}\end{array}$ & $\begin{array}{l}0,051 \\
{[0,693]}\end{array}$ & $\begin{array}{l}0,055 \\
{[0,731]}\end{array}$ & $\begin{array}{c}-0,012 \\
{[-0,160]}\end{array}$ \\
\hline Fator 5: Singularidades $t_{t}$ & $\begin{array}{l}0,024 \\
{[0,357]}\end{array}$ & $\begin{array}{l}0,017 \\
{[0,345]}\end{array}$ & $\begin{array}{l}0,018 \\
{[0,312]}\end{array}$ & $\begin{array}{l}0,019 \\
{[0,363]}\end{array}$ & $\begin{array}{l}0,030 \\
{[0,316]}\end{array}$ & $\begin{array}{l}0,033 \\
{[0,446]}\end{array}$ & $\begin{array}{l}0,024 \\
{[0,455]}\end{array}$ & $\begin{array}{l}0,024 \\
{[0,391]}\end{array}$ & $\begin{array}{l}0,029 \\
{[0,491]}\end{array}$ & $\begin{array}{l}0,044 \\
{[0,422]}\end{array}$ \\
\hline Constante & $\begin{array}{l}0,230^{* *} \\
{[2,254]}\end{array}$ & $\begin{array}{l}0,276^{* *} \\
{[2,053]}\end{array}$ & $\begin{array}{l}0,243^{* *} \\
{[2,253]}\end{array}$ & $\begin{array}{l}0,283^{* * *} \\
{[2,596]}\end{array}$ & $\begin{array}{l}0,347^{* * * *} \\
{[3,054]}\end{array}$ & $\begin{array}{l}0,071 \\
{[0,626]}\end{array}$ & $\begin{array}{l}0,091 \\
{[0,675]}\end{array}$ & $\begin{array}{l}0,085 \\
{[0,740]}\end{array}$ & $\begin{array}{l}0,125 \\
{[1,058]}\end{array}$ & $\begin{array}{l}0,172 \\
{[1,188]}\end{array}$ \\
\hline Dummy de ano & Não & Não & Não & Não & Não & $\operatorname{Sim}$ & $\operatorname{Sim}$ & Sim & Sim & Sim \\
\hline Número de instrumentos & 26,000 & 26,000 & 26,000 & 26,000 & 38,000 & 25,000 & 25,000 & 25,000 & 25,000 & 37,000 \\
\hline Teste de sobreidentificação, de Hansen & 17,961 & 17,224 & 17,826 & 19,343 & 41,884 & 16,042 & 14,908 & 15,665 & 17,133 & 35,481 \\
\hline Teste de Arellano-Bond - AR(1) & $-2,668^{* * *}$ & $-2,681^{* * *}$ & $-2,701^{* * *}$ & $-2,663^{* * *}$ & $-2,445^{* *}$ & $-2,624^{* * *}$ & $-2,646^{* * *}$ & $-2,654^{* * *}$ & $-2,602^{* * *}$ & $-2,460^{* *}$ \\
\hline Teste de Arellano-Bond - AR(2) & $-1,316$ & $-1,339$ & $-1,331$ & $-1,347$ & $-1,266$ & $-1,415$ & $-1,454$ & $-1,439$ & $-1,459$ & $-1,367$ \\
\hline
\end{tabular}

em um período. $N=5253$ e Número de firmas $=203$.

Todas as estimativas incluem um fator macroeconômico. Os instrumentos são a segunda e terceira defasagens.

Fonte: Os autores utilizando o software Stata 14. 
dados financeiros foram coletados do software Economática e a quantidade de patentes e marcas desde 1900 foram coletadas do site do INPI com base no nome e/ou no CNPJ. A razão para coletar séries longas para o cálculo do estoque de patentes e de marcas é reduzir o viés da causalidade reversa que existe nesse modelo. Empresas com valor de mercado maior podem ter mais acesso a crédito para financiar seus investimentos em ativos intangíveis.

Outras duas estratégias também foram utilizadas para reduzir esse viés. A primeira foi utilizar a característica pré-determinada do passado das variáveis e estimar um modelo estático em que as covariadas são defasadas. As limitações dessa estratégia são a perda da relação contemporânea e a hipótese de uma estrutura de defasagem para as covariadas.

Para superar essas restrições, utiliza-se um modelo em painel dinâmico. A segunda estratégia então é aplicar o método de sistema de momentos generalizados em painel, conhecido como system GMM (Arellano \& Bover 1995, Blundell \& Bond 1998). Essa estratégia permite lidar com mais de uma variável endógena e, ao mesmo tempo, estimar o efeito contemporâneo do capital intangível sobre o valor da empresa. A inclusão da parte autorregressiva captura estruturas complexas de defasagens das covariadas.

Para evitar o viés de variável omitida, visto que a literatura de finanças sugere que muitas outras variáveis são passíveis de impactar o valor das ações, foram sintetizadas 14 variáveis específicas das firmas em quatro conjuntos com três, quatro, cinco e seis fatores por meio da Análise Fatorial. Os resultados mostram que somente o fluxo de intangíveis tem efeito positivo e contemporâneo no valor da empresa. O grau de intangibilidade apresentou conclusões ambíguas. Dessa forma, sugere-se que há a valorização do investimento em intangíveis para a manutenção do capital a da competitividade. A sua acumulação ainda deve ser vista com certa apreensão pelos investidores, devido a esse ativo ser mais opaco e de difícil avaliação quando estocado.

O estoque de marcas apresentou um efeito positivo e significativo nos modelos estáticos e defasados. Isso sugere que o efeito de novas marcas no valor da empresa apresenta um efeito defasado no valor das empresas. Sugere-se que essa defasagem possa ser explicada pelas incertezas que investidores têm sobre o estabelecimento de novas marcas no mercado, isto é, investidores avessos ao risco preferem marcas já reconhecidas.

Assim como é comum na literatura, investimentos que visam o desenvolvimento de novas tecnologias, como estoque de patentes, não apresentou efeito significativo. Esse resultado pode ser reflexo de as firmas em países emergentes pautarem o desenvolvimento tecnológico na imitação e difusão.

Uma possível extensão desse trabalho pode ser feita na direção de se estimar modelos não lineares. No processo de linearização, perde-se informação do nível do capital intangível no cálculo da elasticidade. Por exemplo, computa-se o efeito marginal utilizando a Equação (5) como sendo simplesmente o coeficiente da variável de interesse, $\beta_{3}$, para o fluxo de intangíveis. Utilizando as Equações (3) e (4), computa-se a mesma elasticidade como $\frac{\partial \ln \left(\frac{V_{i t}}{T_{i t}}\right)}{\partial \text { FIntg }_{i t}}=\frac{\sigma \theta_{3}}{1+\theta_{1} \text { Qmarcas }_{i t}+\theta_{2} \text { Qpat }_{i t}+\theta_{3} \text { Fintg }_{i t}+\theta_{4} G I_{i t}}$. Outra extensão é explorar a heterogeneidade entre os setores da economia. 


\section{Agradecimentos}

Os autores agradecem suporte do CNPq e Fapemig.

\section{Referências Bibliográficas}

Aboody, D. \& Lev, B. (1998), 'The value relevance of intangibles: the case of software capitalization', Journal of Accounting Research 36, 161-191.

Alencar, R. d. \& Dalmacio, F. Z. (2006), 'A relevância da informação contábil no processo de avaliação de empresas brasileiras - uma análise dos investimentos em ativos intangíveis e seus efeitos sobre value-relevance do lucro e patrimônio líquido', Encontro da ANPAD 30.

Arellano, M. \& Bond, S. (1991), 'Some tests of specification for panel data: Monte Carlo evidence and an application to employment equations', The Review of Economic Studies 58(2), 277-297.

Arellano, M. \& Bover, O. (1995), 'Another look at the instrumental variable estimation of error-components models', Journal of Econometrics 68(1), 2951 .

Arrow, K. J. (1971), The economic implications of learning by doing, in 'Readings in the Theory of Growth', Springer, pp. 131-149.

Belém, V. C. \& Marques, M. d. M. (2012), A influência dos ativos intangíveis na rentabilidade do patrimônio líquido das empresas brasileiras, in 'Congresso USP de Controladoria e Contabilidade', Vol. 12.

Belenzon, S. \& Patacconi, A. (2013), 'Innovation and firm value: an investigation of the changing role of patents, 1985-2007', Research Policy 42(8), 14961510 .

Blundell, R. \& Bond, S. (1998), 'Initial conditions and moment restrictions in dynamic panel data models', Journal of Econometrics 87(1), 115-143.

Bontempi, M. E. \& Mairesse, J. (2015), 'Intangible capital and productivity at the firm level: a panel data assessment', Economics of Innovation and New Technology 24(1-2), 22-51.

Cañibano, L., Garcia-Ayuso, M. \& Sanchez, P. (2000), 'Accounting for intangibles: a literature review', Journal of Accounting Literature 19, 102.

Chauvin, K. W. \& Hirschey, M. (1993), 'Advertising, R\&D expenditures and the market value of the firm', Financial Management pp. 128-140.

Chen, Y.-S. \& Chang, K.-C. (2010), 'The relationship between a firm's patent quality and its market value - the case of US pharmaceutical industry', Technological Forecasting and Social Change 77(1), 20-33.

Cockburn, I. M. \& Griliches, Z. (1987), 'Industry effects and appropriability measures in the stock markets valuation of R\&D and patents'.

da Silva, A., de Souza, T. R. \& Klann, R. C. (2017), 'A influência dos ativos intangíveis na relevância da informação contábil', Revista Contemporânea de Contabilidade 14(31), 26-45. 
da Silva Junior, O. G. \& Pereira, F. F. (2015), 'Ativos intangíveis: pode-se avaliar goodwill e capital intelectual?', Revista de Ciências Gerenciais 14(20).

Decker, F., Ensslin, S. R., Reina, D. R. M. \& Reina, D. (2013), 'A relação entre os ativos intangíveis e a rentabilidade das ações: um estudo com empresas listadas no índice BOVESPA', Reuna 18(4), 75-92.

Fama, E. F. (1970), 'Efficient capital markets: a review of theory and empirical work', The Journal of Finance 25(2), 383-417.

Griliches, Z. (1981), 'Market value, R\&D, and patents', Economics Letters 7(2), 183-187.

Hair, J. F., Black, W. C., Babin, B. J., Anderson, R. E., Tatham, R. L. et al. (1998), Multivariate Data Analysis, Vol. 5, Prentice Hall Upper Saddle River, NJ.

Hall, B. H., Jaffe, A. \& Trajtenberg, M. (2005), 'Market value and patent citations', RAND Journal of Economics pp. 16-38.

Hall, B. H. \& Oriani, R. (2006), 'Does the market value R\&D investment by European firms? Evidence from a panel of manufacturing firms in France, Germany, and Italy', International Journal of Industrial Organization 24(5), 971-993.

Hall, B. H., Thoma, G. \& Torrisi, S. (2007), The market value of patents and R\&D: evidence from European firms, in 'Academy of Management Proceedings', Vol. 2007, Academy of Management, pp. 1-6.

Hansen, L. P. (1982), 'Large sample properties of generalized method of moments estimators', Econometrica: Journal of the Econometric Society pp. 10291054.

Jaffe, A. B. (1986), 'Technological opportunity and spillovers of R\&D: evidence from firms' patents, profits and market value'.

Johnson, R. A., Wichern, D. W. et al. (2014), Applied Multivariate Statistical Analysis, Vol. 4, Prentice-Hall New Jersey.

Kanwar, S. \& Hall, B. H. (2015), The market value of R\&D in weak innovation regimes: evidence from India, Technical report, National Bureau of Economic Research.

Kayo, E. K. (2002), A estrutura de capital e o risco das empresas tangível e intangível-intensivas: uma contribuição ao estudo da valoração de empresas, $\mathrm{PhD}$ thesis, Universidade de São Paulo.

Kayo, E. K., Kimura, H., Martin, D. M. L. \& Nakamura, W. T. (2006), 'Ativos intangíveis, ciclo de vida e criação de valor', Revista de Administração Contemporânea 10(3), 73-90.

Kayo, E. K., Réa Patrocínio, M. \& Leiva Martin, D. M. (2009), 'Intangibilidade e criação de valor em aquisições: o papel moderador do endividamento', $R e$ vista de Administração-RAUSP 44(1). 
Lev, B. (2000), Intangibles: Management, Measurement, and Reporting, Brookings Institution Press.

Lev, B. \& Daum, J. H. (2004), 'The dominance of intangible assets: consequences for enterprise management and corporate reporting', Measuring Business Excellence 8(1), 6-17.

Lima, A. C. \& Carmona, C. U. (2011), 'Determinantes da formação do capital intelectual nas empresas produtoras de tecnologia da informação e comunicação', Revista de Administração Mackenzie 12(1), 112.

Lönnqvist, A. \& Mettänen, P. (2002), Criteria of sound intellectual capital measures, in 'Proceedings of the 2nd International Workshop on Performance Measurement, Hanover, June', pp. 6-7.

Magro, C. B. D., da Silva, A., Padilha, D. F. \& Klann, R. C. (2015), Relevância dos ativos intangíveis em empresas de tecnologia, in ' $9{ }^{\circ}$ Congresso Iberoamericano de Contabilidade e Gestión', Florianópolis.

Megna, P. \& Klock, M. (1993), 'The impact of intangible capital on Tobin's $\mathrm{Q}$ in the semiconductor industry', The American Economic Review 83(2), 265269.

Mendes Nascimento, E., Cerqueira de Oliveira, M., Marques, V. A. \& Veneroso Alves da Cunha, J. (2012), 'Ativos intangíveis: análise do impacto do grau de intangibilidade nos indicadores de desempenho empresarial', Enfoque: Reflexão Contábil 31(1).

Nagaoka, S. (2006), 'R\&D and market value of Japanese firms in the 1990s', Journal of the Japanese and International Economies 20(2), 155-176.

Nonaka, I. \& Takeuchi, H. (2004), Criação de Conhecimento na Empresa, Elsevier Brasil.

Ocean, T. (2015), 'Annual study of intangible asset market value', Disponível em: <http://www.oceantomo.com/2015/03/04/2015-intangible-assetmarket-value-study/>. Acesso em: 10/09/2015.

Oliveira, L., Rodrigues, L. L. \& Craig, R. (2010), 'Intangible assets and value relevance: evidence from the Portuguese stock exchange', The British Accounting Review 42(4), 241-252.

Pemberton, M. \& Rau, N. (2015), Mathematics for Economists: An Introductory Textbook, Oxford University Press.

Penrose, E. T. (2009), The Theory of the Growth of the Firm, Oxford University Press.

Perez, M. M. \& Famá, R. (2006), 'Ativos intangíveis e o desempenho empresarial', Revista Contabilidade \& Finanças 17(40), 7-24.

Romer, P. M. (1986), 'Increasing returns and long-run growth', Journal of Political Economy 94(5), 1002-1037.

Romer, P. M. (1990), 'Endogenous technological change', Journal of political Economy 98(5, Part 2), S71-S102. 
Roodman, D. (2006), 'How to do Xtabond2: an introduction to difference and system GMM in Stata'.

Sandner, P. G. \& Block, J. (2011), 'The market value of R\&D, patents, and trademarks', Research Policy 40(7), 969-985.

Schumpeter, J. A. (2013), Capitalism, Socialism and Democracy, Routledge.

Teece, D. J. (2010), 'Technological innovation and the theory of the firm: the role of enterprise-level knowledge, complementarities, and (dynamic) capabilities', Handbook of the Economics of Innovation 1, 679-730.

Teh, C. C., Kayo, E. K. \& Kimura, H. (2008), 'Marcas, patentes e criação de valor', Revista de Administração Mackenzie (Mackenzie Management Review) 9(1).

Titman, S. \& Wessels, R. (1988), 'The determinants of capital structure choice', The Journal of Finance 43(1), 1-19.

Verbeek, M. \& Nijman, T. (1992), 'Testing for selectivity bias in panel data models', International Economic Review pp. 681-703.

Wooldridge, J. M. (2010), Econometric Analysis of Cross Section and Panel Data, MIT Press.

\section{Apêndice A Variáveis primitivas das firmas e análise fatorial}

Foram operacionalizadas, para cada uma das empresas e para cada um dos anos analisados, 14 variáveis. Essas variáveis são as de maior representatividade nos estudos sobre desempenho das empresas, como pode ser visto em Teh et al. (2008), Perez \& Famá (2006), Kayo (2002), Chauvin \& Hirschey (1993), Titman \& Wessels (1988) e Jaffe (1986). As variáveis e suas respectivas descrições podem ser visualizadas de forma resumida na Tabela 4.

A análise fatorial (AF) foi aplicada sobre as variáveis originais com o objetivo de reduzi-las a um número menor de fatores que pudesse facilitar a interpretação das variáveis latentes e reduzir o problema de multicolinearidade (Johnson et al. 2014). Dessa forma, utilizando o método de componentes principais para extração e o método de rotação Varimax com normalização Kaiser, foi possível descrever e analisar quatro conjuntos de fatores, utilizando o software SPSS 17.0.

A medida de adequabilidade da amostra, obtida pelo teste Kaiser-MeyerOlkin (KMO), é de 0,573. Esse teste pode ser interpretado como a proporção da variância comum entre todas as variáveis. Não há uma regra consensual sobre o valor mínimo que indicaria a inadequação da análise fatorial. Hair et al. (1998) sugerem que valores acima de 0,50 indicam que a análise fatorial é adequada para o conjunto de variáveis.

O teste de esfericidade de Bartlett que testa a hipótese nula de que as variáveis não são correlacionadas apresentou uma estatística de teste de 28052 $(\mathrm{p}$-valor $=0,000)$. Desse modo, não há empecilhos para o uso da análise fatorial.

As variáveis foram agrupadas em quatro conjuntos com três, quatro, cinco e seis fatores. As Tabelas A.2 a A.5 apresentam as cargas fatoriais para cada 
Tabela A.1: Operacionalização e estatísticas descritivas das variáveis de controle e composição dos fatores

\begin{tabular}{|c|c|c|c|c|c|c|c|c|}
\hline \multicolumn{4}{|c|}{ Conj. de fatores } & \multirow{2}{*}{ Interpretação } & \multirow{2}{*}{ Nome da variável } & \multirow{2}{*}{ Operacionalização } & \multirow{2}{*}{ Média } & \multirow{2}{*}{$\begin{array}{l}\text { Desvio } \\
\text { Padrão }\end{array}$} \\
\hline 3 & 4 & 5 & 6 & & & & & \\
\hline 1 & \multirow{3}{*}{1} & \multirow{4}{*}{1} & \multirow{4}{*}{1} & \multirow{4}{*}{ Tamanho } & Ativo total & $\ln ($ Ativo total $)$ & 13,684 & 1,859 \\
\hline 2 & & & & & Receita líquida & $\ln$ (Receita líquida) & 11,344 & 2,282 \\
\hline 1 & & & & & Patrimônio líquido & $\ln$ (Patrimônio líquido) & 12,775 & 2,082 \\
\hline \multirow[t]{2}{*}{2} & 2 & & & & Parcela de mercado & $\begin{array}{l}\text { Receita líquida da empresa/Receita lí- } \\
\text { quida do setor }\end{array}$ & 0,250 & 0,308 \\
\hline & & \multirow[b]{2}{*}{2} & \multirow[b]{2}{*}{2} & \multirow[b]{2}{*}{ Liquidez } & Giro & Receita líquida/Ativo total & 0,183 & 0,155 \\
\hline 1 & 1 & & & & Liquidez & $\begin{array}{l}\text { (Clientes }+ \text { Estoques }- \\
\text { res)/Ativo total }\end{array}$ & 0,152 & 0,144 \\
\hline \multirow{3}{*}{3} & \multirow{2}{*}{3} & \multirow{2}{*}{3} & \multirow{2}{*}{3} & \multirow{2}{*}{ Retorno do acionista } & $\begin{array}{l}\text { Retorno do patrimônio lí- } \\
\text { quido }\end{array}$ & Lucro líquido/PL & $-0,029$ & 1,196 \\
\hline & & & & & $\begin{array}{l}\text { Multiplicador de alavan-- } \\
\text { cagem financeira (MAF) }\end{array}$ & Ativo total/Patrimônio líquido & 5,571 & 36,823 \\
\hline & \multirow{4}{*}{4} & \multirow{4}{*}{4} & \multirow{3}{*}{4} & \multirow{3}{*}{ Riscos relacionados ao ativo } & $\begin{array}{l}\text { Crescimento do ativo } \\
\text { permanente }\end{array}$ & $\begin{array}{l}\text { In(Ativo permanente em } t \text { - Ativo perma- } \\
\text { nente em } t-1) * 100\end{array}$ & 0,033 & 0,185 \\
\hline 2 & & & & & $\begin{array}{l}\text { Crescimento da receita lí- } \\
\text { quida }\end{array}$ & $\begin{array}{l}\text { In(Receita líquida em } t \text { - Receita líquida } \\
\text { em } t-1) * 100\end{array}$ & 0,027 & 0,488 \\
\hline \multirow[b]{2}{*}{3} & & & & & Retorno do ativo & Lucro líquido/Ativo total & 0,013 & 0,043 \\
\hline & & & 5 & Riscos relacionados ao passivo & $\begin{array}{l}\text { Custo líquido do financi- } \\
\text { amento }\end{array}$ & $\begin{array}{l}\text { Resultado financeiro/(Empréstimos de } \\
\text { CP + LP + Debêntures de CP + LP) }\end{array}$ & 0,128 & 14,416 \\
\hline \multirow{2}{*}{2} & \multirow{2}{*}{2} & \multirow{2}{*}{5} & \multirow{2}{*}{6} & \multirow{2}{*}{ Singularidades } & Singularidade & Despesas com vendas/Receita líquida & 0,176 & 2,416 \\
\hline & & & & & Margem líquida & Lucro líquido/Receita líquida & 92,906 & 5694,162 \\
\hline
\end{tabular}

Fonte: Elaboração própria com base nos dados das empresas para o período de 2000 a 2014 utilizando SPSS 17. 
conjunto juntamente com a porcentagem da variância explicada pelos fatores. A proporção da variância explicada está entre $44,84 \%$ e $63,83 \%$. Observa-se que os componentes de cada fator não apresentam grande variação entre os conjuntos, sendo a maior diferença no menor conjunto.

Propõe-se uma interpretação para os fatores com base nos dois maiores conjuntos e observando que com a redução do número de elementos, de forma geral, há uma agregação de dois ou mais fatores:

Fator 1 - Tamanho da firma. Os coeficientes do logaritmo do ativo total, da receita total e do patrimônio líquido são os componentes com maiores cargas positivas e com valores muito próximos. A parcela de mercado da firma, que reflete seu tamanho frente aos concorrentes, também pertence a esse componente com carga considerável.

Fator 2 - Liquidez. Esse fator congrega a liquidez da empresa em termos do ativo circulante e giro do ativo total.

Fator 3 - Rentabilidade dos sócios. Para tal componente, tem-se que as variáveis de retorno do patrimônio líquido e o multiplicador de alavancagem financeira apresentam as maiores cargas. O segundo componente apresentou sinal negativo.

Fator 4 - Riscos relacionados ao ativo. Esse fator sintetiza a capacidade da firma em fazer crescer suas receitas e patrimônio líquido e, consequentemente, aumentar seu retorno.

Fator 5 - Riscos relacionados ao passivo. Esse fator incorpora o risco por meio do custo do financiamento que, apesar de apresentar carga alta, é positiva. A união dos fatores 4 e 5 forma um fator de risco para as empresas quando observamos o conjunto com cinco fatores (Tabela A.4). Nesse conjunto, sua carga é relativamente baixa, mas se mantém positiva.

Fator 6 - Singularidade. Em geral, o esforço de vendas (maiores despesas com vendas) é usado como proxy para singularidade. A análise fatorial revelou que essa variável é positivamente relacionada à margem líquida obtida pela firma também.

Para o terceiro conjunto, a principal diferença comparada com os conjuntos maiores está na composição dos dois primeiros fatores. O logaritmo do ativo total, receita total e patrimônio líquido entram no primeiro fator com carga positiva enquanto que o índice de liquidez tem carga negativa e ligeiramente superior, em valor absoluto, do que a carga que tem no segundo fator, cujo sinal é positivo. A parcela de mercado e Giro forma o segundo fator. Os outros são semelhantes ao conjunto de cinco fatores.

\section{Apêndice B Variáveis primitivas macroeconômicas e análise fatorial}

As variáveis relacionadas ao ambiente macroeconômico e suas estatísticas descritivas estão apresentadas na Tabela B.1. Todas as variáveis estão em variações decimais. Elas foram agrupadas em três conjuntos com um, dois e três fatores. O valor do teste Kaiser-Meyer-Olkin (KMO) é 0,514, mostrando que a análise fatorial é adequada na redução da dimensionalidade e, o teste de esfericidade Bartlett mostra uma estatística de 64,36 (p-valor $=0,000$ ) rejeitando a hipótese nula de que essas variáveis não são correlacionadas.

A Tabela B. 2 mostra o primeiro conjunto com um único fator. A taxa de juros e desemprego apresentam as maiores cargas fatoriais com sinal positivo. $\mathrm{O}$ 
Tabela A.2: Matriz fatorial rotacionadas pelo método VARIMAX para o conjunto de três fatores

\begin{tabular}{lrrr}
\hline \multicolumn{1}{c}{ Variáveis } & $\mathbf{1}$ & \multicolumn{1}{c}{ Componentes } & \multicolumn{1}{c}{$\mathbf{3}$} \\
\hline $\ln$ (Ativo total) & $\mathbf{0 , 9 5 0}$ & 0,180 & 0,083 \\
$\ln$ (Patrimônio líquido) & $\mathbf{0 , 9 0 1}$ & 0,158 & 0,251 \\
Liquidez & $-\mathbf{0 , 6 4 8}$ & 0,414 & 0,161 \\
$\ln$ (Receita líquida) & 0,580 & $\mathbf{0 , 6 8 4}$ & 0,140 \\
Giro & $-0,551$ & $\mathbf{0 , 6 7 1}$ & 0,145 \\
Market share & 0,115 & $\mathbf{0 , 6 1 2}$ & 0,048 \\
Crescimento da receita líquida & $-0,004$ & $\mathbf{0 , 2 6 6}$ & 0,127 \\
Singularidade & $-0,023$ & $-\mathbf{0 , 2 0 9}$ & 0,067 \\
Margem líquida & 0,012 & $-\mathbf{0 , 1 1 8}$ & 0,029 \\
Retorno do patrimônio líquido & 0,015 & $-0,154$ & $\mathbf{0 , 8 4 2}$ \\
MAF & $-0,058$ & 0,182 & $-\mathbf{0 , 7 6 5}$ \\
Retorno do ativo & 0,035 & 0,208 & $\mathbf{0 , 5 0 4}$ \\
Crescimento do ativo permanente & 0,022 & 0,058 & $\mathbf{0 , 1 5 0}$ \\
Custo líquido do financiamento & 0,000 & $-0,004$ & $\mathbf{0 , 0 4 0}$ \\
\hline Variância explicada acumulada (\%) & 19,950 & 32,467 & 44,849 \\
\hline Fonte: Os autores utilizando o software SPSS 17 & &
\end{tabular}

Tabela A.3: Matriz fatorial rotacionadas pelo método VARIMAX para o conjunto de quatro fatores

\begin{tabular}{lrrrr}
\hline \multicolumn{1}{c}{ Variáveis } & \multicolumn{4}{c}{ Componentes } \\
& $\mathbf{1}$ & \multicolumn{1}{c}{$\mathbf{2}$} & \multicolumn{1}{c}{$\mathbf{3}$} & \multicolumn{1}{c}{4} \\
\hline $\ln ($ Ativo total) & $\mathbf{0 , 9 6 5}$ & 0,089 & 0,034 & 0,029 \\
$\ln$ (Patrimônio líquido) & $\mathbf{0 , 9 2 1}$ & 0,088 & 0,205 & 0,055 \\
$\ln ($ Receita líquida) & $\mathbf{0 , 6 5 0}$ & 0,634 & 0,056 & 0,079 \\
Liquidez & $-\mathbf{0 , 5 9 6}$ & 0,502 & 0,153 & 0,029 \\
Giro & $-0,476$ & $\mathbf{0 , 7 3 5}$ & 0,096 & 0,094 \\
Market share & 0,178 & $\mathbf{0 , 6 2 4}$ & 0,014 & $-0,031$ \\
Singularidade & $-0,044$ & $-\mathbf{0 , 2 3 9}$ & 0,037 & 0,154 \\
Margem líquida & 0,002 & $-\mathbf{0 , 1 1 4}$ & 0,042 & $-0,014$ \\
Retorno do patrimônio líquido & 0,035 & $-0,070$ & $\mathbf{0 , 8 5 6}$ & 0,106 \\
MAF & $-0,075$ & 0,071 & $-\mathbf{0 , 8 3 0}$ & 0,066 \\
Crescimento do ativo permanente & 0,021 & $-0,093$ & $-0,061$ & $\mathbf{0 , 6 9 0}$ \\
Crescimento da receita líquida & 0,016 & 0,138 & $-0,073$ & $\mathbf{0 , 6 0 9}$ \\
Retorno do ativo & 0,066 & 0,132 & 0,331 & $\mathbf{0 , 5 8 3}$ \\
Custo líquido do financiamento & $-0,001$ & $-0,027$ & 0,006 & $\mathbf{0 , 1 1 7}$ \\
\hline Variância explicada acumulada (\%) & 20,223 & 32,541 & 44,127 & 53,125 \\
\hline Fonte: Os autores utilizando & & & &
\end{tabular}

Fonte: Os autores utilizando o software SPSS 17. 
Tabela A.4: Matriz fatorial rotacionadas pelo método VARIMAX para o conjunto de cinco fatores

\begin{tabular}{lrrrrr}
\hline \multicolumn{1}{c}{ Variáveis } & $\mathbf{5}$ & $\mathbf{2}$ & \multicolumn{1}{c}{$\mathbf{3}$} & \multicolumn{1}{c}{$\mathbf{4}$} & \multicolumn{1}{c}{$\mathbf{5}$} \\
\hline $\ln ($ Ativo total) & $\mathbf{0 , 8 7 8}$ & $-0,413$ & 0,038 & 0,034 & 0,028 \\
$\ln$ (Receita líquida) & $\mathbf{0 , 8 7 5}$ & 0,192 & $-0,001$ & 0,065 & $-0,164$ \\
$\ln$ (Patrimônio líquido) & $\mathbf{0 , 8 4 9}$ & $-0,369$ & 0,207 & 0,058 & 0,038 \\
Market share & $\mathbf{0 , 4 9 1}$ & 0,458 & $-0,077$ & $-0,053$ & 0,048 \\
Giro & $-0,018$ & $\mathbf{0 , 8 8 8}$ & $-0,013$ & 0,062 & $-0,052$ \\
Liquidez & $-0,239$ & $\mathbf{0 , 7 5 9}$ & 0,071 & 0,004 & $-0,022$ \\
Retorno do patrimônio líquido & 0,031 & 0,023 & $\mathbf{0 , 8 6 3}$ & 0,104 & 0,014 \\
MAF & $-0,055$ & 0,017 & $-\mathbf{0 , 8 4 4}$ & 0,067 & 0,043 \\
Crescimento do ativo permanente & $-0,022$ & $-0,067$ & $-0,050$ & $\mathbf{0 , 6 9 3}$ & 0,041 \\
Crescimento da receita líquida & 0,032 & 0,041 & $-0,036$ & $\mathbf{0 , 6 1 2}$ & $-0,446$ \\
Retorno do ativo & 0,174 & 0,177 & 0,288 & $\mathbf{0 , 5 7 2}$ & 0,211 \\
Custo líquido do financiamento & $-0,001$ & $-0,001$ & $-0,001$ & $\mathbf{0 , 1 1 6}$ & 0,096 \\
Singularidade & $-0,063$ & $-0,036$ & $-0,022$ & 0,147 & $\mathbf{0 , 7 5 3}$ \\
Margem líquida & 0,006 & $-0,006$ & $-0,001$ & $-0,020$ & $\mathbf{0 , 4 8 3}$ \\
\hline Variância explicada acumulada (\%) & 18,544 & 32,527 & 43,956 & 52,871 & 60,658 \\
\hline Fonte: Os aur
\end{tabular}

Fonte: Os autores utilizando o software SPSS 17.

Tabela A.5: Matriz fatorial rotacionadas pelo método VARIMAX para o conjunto de seis fatores

\begin{tabular}{lrrrrrr}
\hline \multicolumn{1}{c}{ Variáveis } & $\mathbf{7}$ & $\mathbf{2}$ & $\mathbf{3}$ & \multicolumn{1}{c}{ Componentes } & \multicolumn{1}{c}{$\mathbf{5}$} & \multicolumn{1}{c}{$\mathbf{6}$} \\
\hline $\ln$ (Ativo total) & $\mathbf{0 , 8 7 9}$ & $-0,411$ & 0,038 & 0,031 & 0,017 & 0,029 \\
$\ln$ (Receita líquida) & $\mathbf{0 , 8 7 5}$ & 0,194 & $-0,001$ & 0,070 & 0,018 & $-0,161$ \\
$\ln$ (Patrimônio líquido) & $\mathbf{0 , 8 5 0}$ & $-0,367$ & 0,206 & 0,053 & 0,028 & 0,040 \\
Market share & $\mathbf{0 , 4 9 1}$ & 0,460 & $-0,076$ & $-0,042$ & $-0,107$ & 0,052 \\
Giro & $-0,020$ & $\mathbf{0 , 8 8 8}$ & $-0,013$ & 0,063 & 0,013 & $-0,049$ \\
Liquidez & $-0,240$ & $\mathbf{0 , 7 5 8}$ & 0,071 & 0,001 & 0,026 & $-0,023$ \\
Retorno do patrimônio líquido & 0,031 & 0,024 & $\mathbf{0 , 8 6 3}$ & 0,100 & 0,019 & 0,019 \\
MAF & $-0,056$ & 0,017 & $-\mathbf{0 , 8 4 5}$ & 0,063 & 0,039 & 0,044 \\
Crescimento do ativo permanente & $-0,021$ & $-0,066$ & $-0,045$ & $\mathbf{0 , 7 1 0}$ & $-0,116$ & 0,084 \\
Crescimento da receita líquida & 0,032 & 0,042 & $-0,035$ & $\mathbf{0 , 6 2 8}$ & 0,066 & $-0,418$ \\
Retorno do ativo & 0,174 & 0,177 & 0,288 & $\mathbf{0 , 5 4 5}$ & 0,165 & 0,231 \\
Custo líquido do financiamento & $-0,005$ & $-0,005$ & $-0,019$ & $-0,008$ & $\mathbf{0 , 9 6 0}$ & 0,045 \\
Singularidade & $-0,063$ & $-0,036$ & $-0,019$ & 0,129 & $-0,117$ & $\mathbf{0 , 7 6 7}$ \\
Margem líquida & 0,005 & $-0,006$ & $-0,003$ & $-0,056$ & 0,116 & $\mathbf{0 , 4 7 5}$ \\
\hline Variância explicada acumulada (\%) & 18,562 & 32,533 & 43,961 & 52,848 & 60,057 & 67,830 \\
\hline Fonte: Os autores utilizando
\end{tabular}

Fonte: Os autores utilizando o software SPSS 17. 
crescimento do PIB também apresenta carga positiva, mas substancialmente menor. A taxa de inflação e variação do câmbio têm cargas negativas e próximas de zero. A variância explicada pelo fator é de 39,1\%.

No conjunto dois, exposto na Tabela B.3, o primeiro fator ainda é composto pela taxa de juros e desemprego e as outras variáveis compõem o segundo fator. Somente a carga fatorial da variação do câmbio é negativa e próxima de zero. Esses dois fatores conseguem explicar $61,29 \%$ da variância.

O terceiro conjunto (Tabela B.4) é semelhante ao segundo e a única diferente está na separação da variação cambial em um terceiro fator. A variância explicada por esses três fatores é de $80,75 \%$.

Tabela B.1: Estatísticas descritivas das variáveis macroeconômicas

\begin{tabular}{lcc}
\hline \multicolumn{1}{c}{ Variáveis } & Média & Desvio padrão \\
\hline Taxa de desemprego & 0,101 & 0,015 \\
Variação do câmbio & 0,007 & 0,091 \\
Taxa de inflação (IPCA) & 0,016 & 0,010 \\
Taxa básica de juros (Selic) & 0,033 & 0,010 \\
Crescimento do PIB & 0,033 & 0,024 \\
\hline
\end{tabular}

Fonte: Os autores utilizando o software SPSS 17.

Tabela B.2: Matriz fatorial rotacionadas pelo método VARIMAX para o conjunto de um fator

\begin{tabular}{lc}
\hline \multicolumn{1}{c}{ Variáveis } & Componente \\
\hline Taxa de juros & $\mathbf{0 , 9 2 4}$ \\
Taxa de desemprego & $\mathbf{0 , 8 9 5}$ \\
Crescimento do PIB & $\mathbf{0 , 5 1 0}$ \\
Taxa de inflação & $\mathbf{0 , 1 8 1}$ \\
Variação do câmbio & $\mathbf{- 0 , 0 8 4}$ \\
\hline Variância explicada acumulada (\%) & 39,091 \\
\hline Fonte: Os autores utilizando o software SPSS 17.
\end{tabular}


Tabela B.3: Matriz fatorial rotacionadas pelo método VARIMAX para o conjunto de dois fatores

\begin{tabular}{lrr}
\hline \multicolumn{1}{c}{ Variáveis } & \multicolumn{2}{c}{ Componentes } \\
& $\mathbf{1}$ & \multicolumn{1}{c}{$\mathbf{2}$} \\
\hline Taxa de juros & $\mathbf{0 , 9 3 0}$ & 0,079 \\
Taxa de desemprego & $\mathbf{0 , 9 0 7}$ & 0,051 \\
Crescimento do PIB & $-0,266$ & $\mathbf{0 , 7 7 2}$ \\
Taxa de inflação & 0,379 & $\mathbf{0 , 6 2 1}$ \\
Variação do câmbio & $-0,092$ & $-\mathbf{0 , 4 0 4}$ \\
\hline Variância explicada acumulada (\%) & 39,091 & 61,291 \\
\hline Fonte: Os autores utilizando o software SPSS 17.
\end{tabular}

Tabela B.4: Matriz fatorial rotacionadas pelo método VARIMAX para o conjunto de três fatores

\begin{tabular}{lrrr}
\hline \multicolumn{1}{c}{ Variáveis } & \multicolumn{3}{c}{ Componentes } \\
& $\mathbf{1}$ & \multicolumn{1}{c}{$\mathbf{2}$} & \multicolumn{1}{c}{$\mathbf{3}$} \\
\hline Taxa de juros & $\mathbf{0 , 9 4 0}$ & 0,026 & 0,013 \\
Taxa de desemprego & $\mathbf{0 , 9 0 6}$ & $-0,032$ & $-0,057$ \\
Crescimento do PIB & $-0,179$ & $\mathbf{0 , 8 7 1}$ & 0,050 \\
Taxa de inflação & 0,429 & $\mathbf{0 , 5 8 5}$ & $-0,142$ \\
Variação do câmbio & $-0,029$ & $-0,025$ & $\mathbf{0 , 9 9 3}$ \\
\hline Variância explicada acumulada (\%) & 38,454 & 60,491 & 80,749 \\
\hline
\end{tabular}

Fonte: Os autores utilizando o software SPSS 17. 